Review

\title{
(+)-Podocarpic Acid as Chiral Template in the Synthesis of Aphidicolane, Stemodane and Stemarane Diterpenoids ${ }^{\dagger}$
}

\author{
Angela La Bella ${ }^{1}$, Francesca Leonelli ${ }^{2}$, Luisa Maria Migneco ${ }^{1}$ and Rinaldo Marini Bettolo ${ }^{1, *}$ \\ 1 Dipartimento di Chimica, Università degli Studi di Roma “La Sapienza”, P.le Aldo Moro, 5, I-00185 Roma, \\ Italy; angela.labella@uniroma1.it (A.L.B.); luisamaria.migneco@uniroma1.it (L.M.M.) \\ 2 Dipartimento di Biologia Ambientale, Università degli Studi di Roma "La Sapienza", P.le Aldo Moro, 5, \\ I-00185 Roma, Italy; francesca.leonelli@uniroma1.it \\ * Correspondence: rinaldo.marinibettolo@uniroma1.it; Tel.: +39-649-913-615; Fax: +39-6445-7047 \\ $\dagger$ Dedicated to Professor Karel Wiesner, our unforgotten mentor, on the thirtieth anniversary of his death. \\ Academic Editors: Carlo Siciliano and Constantinos M. Athanassopoulos \\ Received: 6 August 2016; Accepted: 2 September 2016; Published: 8 September 2016
}

\begin{abstract}
In this review the synthetic work in the field of aphidicolane, stemodane and stemarane diterpenoids, in which readily available (+)-podocarpic acid (4) was used as chiral template for the construction of their polycyclic structures, is described as it developed along the years. In the frame of this work (+)-podocarpic acid (4) was a very useful tool in a model study leading to the syntheses of tetracyclic ketones $\mathbf{7}$ and $\mathbf{8}$, models of key intermediates $\mathbf{5 a}$ and $\mathbf{6}$ in the syntheses of $(+)$-aphidicolin (1) and (+)-stemodin (2a), respectively. (+)-Podocarpic acid (4) was also converted into (+)-2-deoxystemodinone (2d), allowing confirmation of the stemodane diterpenoids absolute configuration, into (+)-aphidicol-15-ene (36) and into Stemodia chilensis tetracyclic diterpenoid $(+)$-19-acetoxystemodan-12-ol (2f), allowing confirmation of its structure. (+)-Podocarpic acid (4) was then extensively used in the work which led to the synthesis of $(+)$-stemar-13-ene (57) and $(+)$-18-deoxystemarin (3b). Finally, (+)-4 was converted into (+)-2-deoxyoryzalexin S (66), which made it possible to demonstrate that the structure of (+)-66 could not be attributed to a Chilean Calceolaria isolated diterpenoid to which this structure had been assigned.
\end{abstract}

Keywords: aphidicolin; stemodin; stemarin; podocarpic acid; synthesis

\section{Aphidicolane, Stemodane and Stemarane Diterpenoids}

Between 1970 and 1980 three new classes of tetracyclic diterpenes, whose C/D ring system is constituted by a bicyclo[3.2.1]octane system, were isolated. The parent compounds of these classes are: (+)-aphidicolin (1), (+)-stemodin (2) and (+)-stemarin (3a) (Figure 1). (+)-Aphidicolin (1), which showed interesting biological properties, was isolated in 1972 from the fungus Cephalosporium aphidicola Petch [1,2]. (+)-Stemodin (2a) was isolated in 1973, along with (+)-stemodinone (2b), from Stemodia maritima L. [3]. In 1975 (+)-stemarin (3a) [4] and stemodane diterpenoid maritimol (2c) [5] were also isolated from the same plant. The number of isolated diterpenoids of these classes grew in the following years. After the disclosure of these new and interesting structures various research groups over the world decided to engage themselves in the synthesis of these tetracyclic diterpenoids. Some among these groups decided to enter the field starting from the preformed system of (+)-podocarpic acid (4) (Figure 1) [6]. Hereafter the work of the latter groups is described the way it developed along the years. 


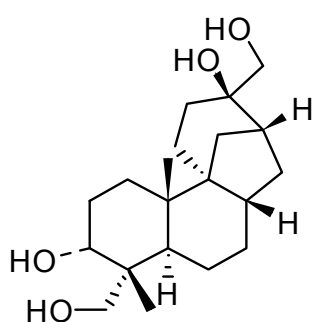

$(+)-1$

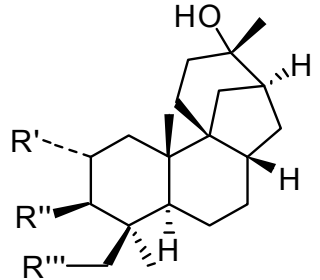

(+)-2a R'=OH, R"=H, R'"=H

(+)-2b R'=O, R"=H, R'"=H

(+)-2c R'=H, R"=OH, R'"=H

(+)-2d R'=H, R"=H, R'"=H

$(+)-2 e R^{\prime}=H, \quad R "=H, \quad R^{\prime \prime \prime}=\mathrm{OH}$

(+)-2f $R^{\prime}=H, \quad R^{\prime \prime}=H, \quad R '=O A c$

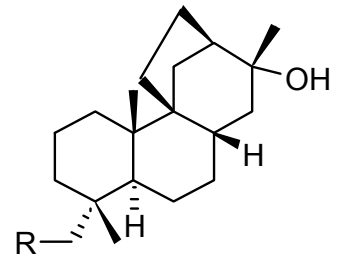

(+)-3a R=OH

$(+)-3 b \quad R=H$<smiles>C[C@]12CCCC[C@]1(C)CCc1ccc(O)cc12</smiles>

$(+)-4$

podocarpic acid

Figure 1. Aphidicolin 1, stemodane diterpenoids 2, stemarane diterpenoids 3 and podocarpic acid 4.

The first two formal total syntheses of $( \pm$ )-aphidicolin (1) were published at the beginning of $1979[7,8]$. Both syntheses had as a target compound $5 \mathbf{a}$, the acetonide of the periodic acid cleavage product of (+)-1, reconverted, though not diastereoselectively into (+)-1 [2]. This synthetic problem was overcome in 1988 when a solution to it was described $[9,10]$. Later syntheses of $( \pm)-\mathbf{1}$ via $\mathbf{5 a}$ and $\mathbf{5 b}$ (Figure 2) were published also by other groups [11-19]. Enantioselective total syntheses of (+)-1 via $\mathbf{5 a}$ and $\mathbf{5 b}$ were also described [20-22]. In 1980 the first total synthesis of $( \pm$ )-stemodin $\mathbf{2 a}$ and $( \pm$ )-stemodinone $\mathbf{2} \mathbf{b}$ via the tetracyclic ketone $\mathbf{6}$ (Figure 2 ) was also published [23].

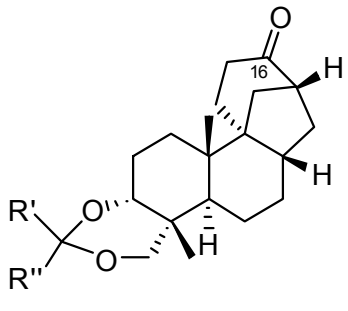

$5 a R^{\prime}=H^{\prime \prime}=H$

$5 b R^{\prime}=H R^{\prime \prime}=t-B u$

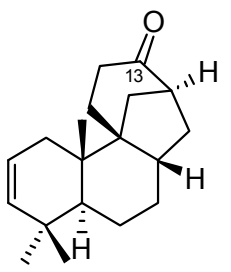

6

Figure 2. Key synthetic intermediates in the synthesis of $\mathbf{1}$ and $\mathbf{2 a}, \mathbf{2 b}, \mathbf{2 d}$.

\section{1982 Synthesis of 17-Noraphidicolan-16-one and 17-Norstemodan-16-one from (+)-Podocarpic Acid via (-)-9(11)-Podocarpen-12-one (1982)}

Between 1976 and 1978 one of us (RMB) had been involved, as a member of the Wiesner group at the University of New Brunswick (Fredericton, NB, Canada), in the synthesis of some diterpene alkaloids whose C/D ring system, constituted by a bicyclo[3.2.1] octane system, was obtained by the bicyclo[2.2.2]octane $\rightarrow$ bicyclo[3.2.1]octane skeletal rearrangement [24-26]. The end of this fruitful and exciting experience coincided with the disclosure of the first two syntheses of $( \pm)$-aphidicolin $(\mathbf{1})[7,8]$. Thus, back in Rome, we desired to show that the approach developed by Wiesner for the construction of the C/D ring system of diterpene alkaloids [27-30] could be also particularly convenient for the synthesis of the aphidicolane and stemodane systems. In fact the above rearrangement would have not only produced the required bicyclo[3.2.1]octane system but also introduced the oxygenated function present at $\mathrm{C}-16$ in $\mathbf{5 a}$ and at $\mathrm{C}-13$ in $\mathbf{6}$. Our initial aim was, therefore, that of showing the usefulness of this strategy by obtaining the tetracyclic ketones 7 and 8 which differ from $5 a$ and $\mathbf{6}$ only in the A ring substitution, respectively. This choice would permit adoption of (+)-podocarpic acid (4) as starting material. 


\subsection{Retrosynthetic Analysis and Strategy}

The approach adopted by us for obtaining 7 and 8 was based on the following retrosynthetic analysis: (a) obtaining the bicyclo[3.2.1] octane system by rearrangement of a bicyclo[2.2.2] octane intermediate [31-34]; (b) obtaining the bicyclo[2.2.2]octane intermediate by intramolecular aldol reaction [35-37]; (c) stereoselective addition of a $-\mathrm{CH}_{2} \mathrm{CHO}$ unit or synthetic equivalent from the $\alpha$ face to the $C(9)$ of (-)-9(11)-podocarpen-12-one intermediate 10a. For the sake of precision the synthesis of $( \pm)-\mathbf{1}$ described in ref. [12] also proceeds via a 9(11)-podocarpen-12-one and is also based on the bicyclo[2.2.2] octane $\rightarrow$ bicyclo[3.2.1]octane skeletal rearrangement; in this synthesis the bicyclo[2.2.2] octane system is obtained by Diels-Alder addition. Previously a synthesis of $( \pm)-2 \mathrm{c}$ based on the same approach was also described [38].

As it can be observed (Scheme 1) the migrating bond is always the same one. Nevertheless, the different location of the leaving group causes its migration via the upper or lower face, leading to the stemodane and aphidicolane systems, respectively.

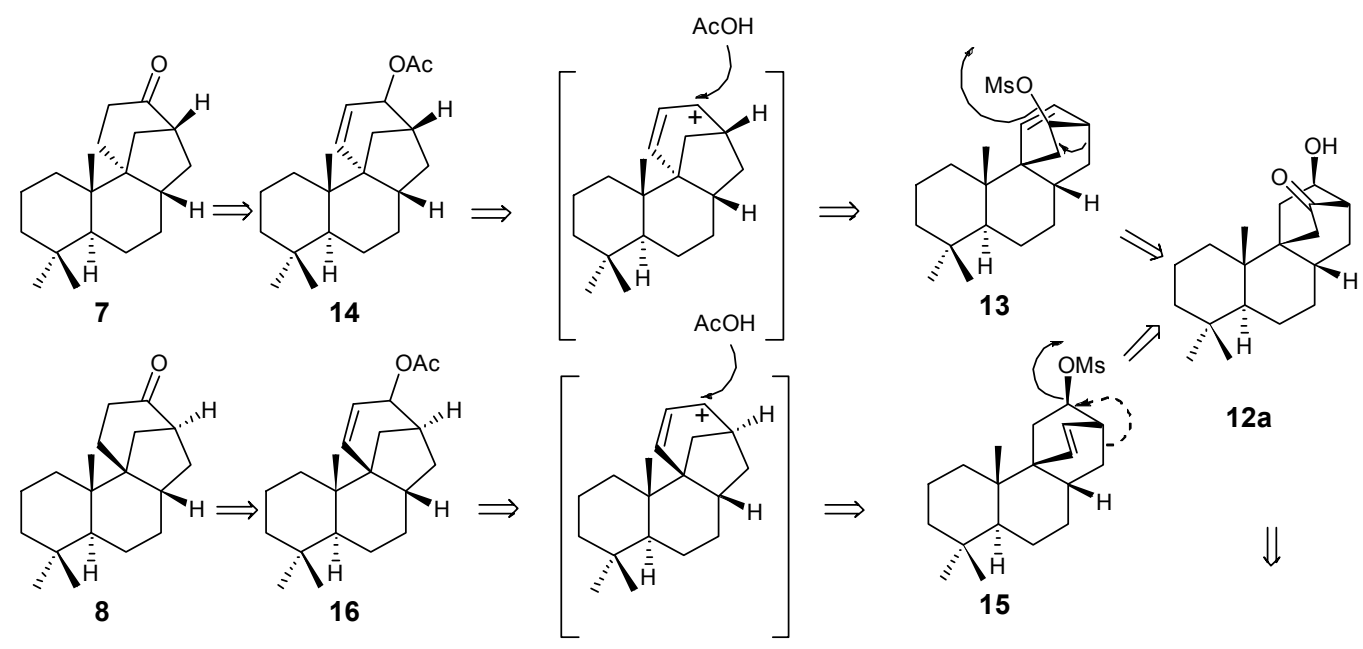<smiles>C=CC1(C)c2cc(O)ccc2CC[C@@H]2[C@H]1CCC[C@@]2(C)C(=O)O</smiles>

$(+)-4$

podocarpic acid<smiles>COc1ccc2c(c1)[C@]1(C)CCCC(C)(C)[C@H]1CC2</smiles>

9

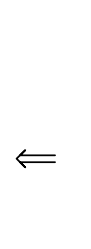<smiles>C[C@@H]1CCC[C@]2(C)C3=CC(=O)CC[C@H]3CC[C@@]12C</smiles>

$(-)-10 a$<smiles>C[C@H]1CCC[C@@]2(C)[C@H]1CC[C@H]1CCC(=O)C[C@]12C=O</smiles>

11

Scheme 1. Retrosynthetic analysis of the preparation of tetracyclic ketones 7 and 8 .

2.2. (+)-Podocarpic Acid as Chiral Template and (-)-9(11)Podocarpen-12-one as Suitable Chiron for Obtaining of 17-Noraphidicolan-16-one and 17-Norstemodan-16-one

The commercially available (Aldrich) chiral template [39] (+)-podocarpic acid (4) appeared to us a suitable starting material for a quick evaluation of our working hypothesis. In fact, it shows a good overlap of the skeleton and correctly set-up stereogenic centers at $C(5)$ and $C(10)$.

Besides, it was also known that the Birch reduction of 9, available in few steps from (+)-podocarpic acid (4), followed by acidic cleavage of the resulting dienol ether gives the chiron [39] (-)-9(11)podocarpen-12-one (10a) whose vinylogous $\mathrm{H}-\mathrm{C}(8)$ is $\beta$-oriented as required [40] (Scheme 2). This is because the structure 10a is thermodynamically more stable than the epimeric one 10b in which the $\mathrm{H}-\mathrm{C}(8)$ is $\alpha$ oriented [41]. 


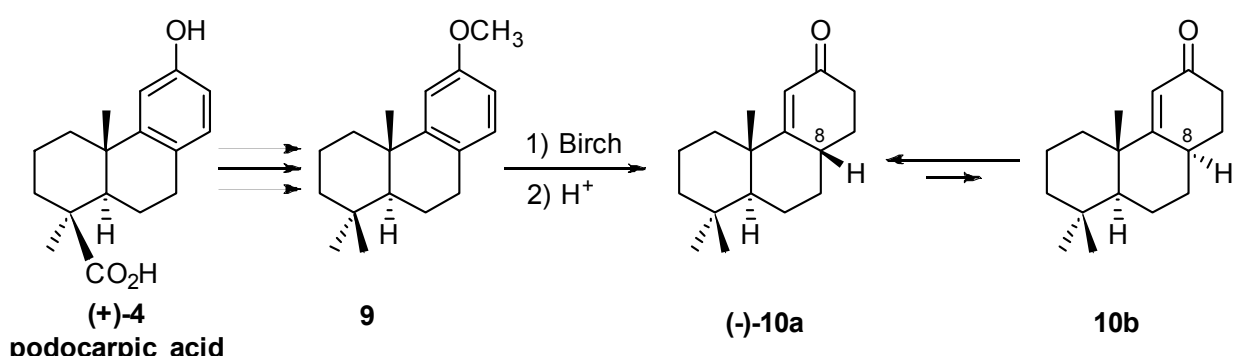

Scheme 2. Birch reduction of podocarpic acid derivative 9 to give after acidic hydrolysis (-)-9(11)podocarpen-12-one (10a).

Therefore the use of (+)-podocarpic acid (4) as starting material would have also resulted in the correct installment of the stereocenter at $C(8)$ and generate a handle (the ring $C \alpha, \beta$-unsaturated ketone) for the construction of the bicyclo[2.2.2]octane intermediate by the Wiesner two-carbon annulation sequence [42].

\subsection{Synthesis of 17-Noraphidicolan-16-one (1982)}

The starting material for the synthesis of 7 (Scheme 3) was (-)-9(11)-podocarpen-12-one (10a). Allene photoaddition to 10a in THF at $-78^{\circ} \mathrm{C}$ gave the photoadduct (+)-17. The stereochemistry of the addition was hypothesized on the basis of the Wiesner empirical rule [43-46] and later confirmed by the preparation of the expected final product. Nowadays the regio- and stereochemistry of the allene photoaddition can be established by 2D-NMR experiments (see Section 7). The exocyclic methylene in acetal 18, obtained from (+)-17 by standard methods, was then converted into the cyclobutanol 19 by oxidative cleavage followed by reduction. Treatment of the latter with diluted $\mathrm{HCl}$ unmasked the carbonyl function and effected cyclobutanol ring opening by a retro-aldol reaction (see Section 8.1). Subsequent diluted $\mathrm{NaOH}$ treatment in $\mathrm{MeOH}$ afforded 12 as a mixture of epimers at $\mathrm{C}(12)$. In order to obtain the aphidicolane system three synthetic operations were required:

a. protection of the HO-C(12);

b. reduction of the carbonyl group to the corresponding $15 \alpha$-alcohol;

c. introduction of a double bond at $\mathrm{C}(11)$ in order to make the rearrangement quantitative.

This was achieved by transforming the $\mathrm{HO}-\mathrm{C}(12)$ into the corresponding dithiocarbonate 20. Subsequent reduction of the carbonyl group with $\mathrm{NaBH}_{4}$ gave stereoselectively the desired alcohol 21 owing to the bulkiness of the dithiocarbonate group. The following Chugaev reaction gave finally the unsaturated alcohol 22 which was then transformed into the methanesulfonate 13. The latter, submitted to solvolysis in glacial acetic acid, gave the rearranged acetate 14 (see Section 8.2). Saponification of the latter followed by oxidation with $\mathrm{PCC} / \mathrm{Al}_{2} \mathrm{O}_{3}$ afforded the enone $\mathbf{2 4}$ which was eventually reduced to the target ketone 7 [47], identical with an authentic sample kindly donated by Dr. B. Hesp (ICI Americas Inc., Wilmington, DE, USA) and Dr. A.H. Ratcliffe (ICI Ltd. Macclesfield, UK).

\subsection{Synthesis of 17-Norstemodan-16-one (1982)}

The starting material for the obtaining of 8 was the ketol 12a (vide supra). Thus 12a was converted (Scheme 4) into the tetrahydropyranyl derivative 25 by standard methods. The latter was then reduced with $\mathrm{NaBH}_{4}$ to give the alcohol 26 which was transformed into the dithiocarbonate 27. Pyrolysis of $\mathbf{2 7}$ gave then the unsaturated alcohol $\mathbf{2 8}$ which was converted into the corresponding mesylate $\mathbf{1 5}$. The latter on heating in glacial AcOH underwent rearrangement to give $\mathbf{1 6}$ (see Section 8.2) which was converted into 8 by saponification followed by oxidation and catalytic hydrogenation [47]. Its structure was confirmed by its conversion into (+)-stemod-12-ene (31), identical with an authentic sample kindly donated by Dr. P. S. Manchand (Hoffmann-La Roche Inc., Nutley, NJ, USA). 

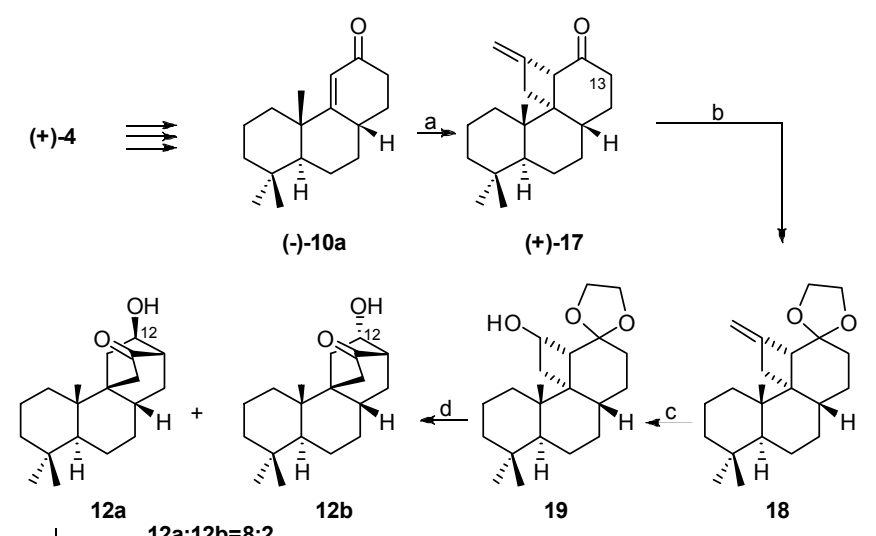<smiles>[TeH]</smiles>

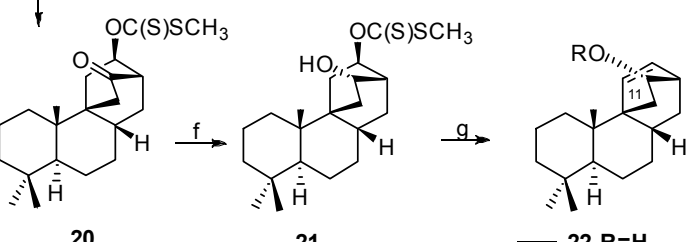

20

21<smiles>CC1CCCC2(C)C(C)CC(=O)CCC12</smiles><smiles>CC1CCCC23CCC(=O)CC2CCC3C1</smiles>

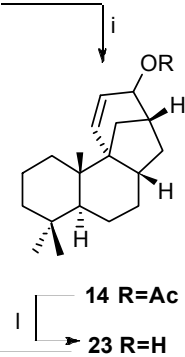

Scheme 3. Synthesis of 17-Noraphidicolan-16-one. Reagents and conditions: (a) allene, hv, pyrex, $-78{ }^{\circ} \mathrm{C}$, THF, quantitative yield; (b) ethylene glycol, $\mathrm{TsOH}$, benzene, reflux; (c) $\mathrm{O}_{3}, \mathrm{EtOH} / \mathrm{CH}_{2} \mathrm{Cl}_{2}=1: 1$, $-78{ }^{\circ} \mathrm{C} / \mathrm{NaBH}_{4}$; (d) (1) THF $/ 1 \mathrm{~N} \mathrm{HCl}=2: 1$; (2) $\mathrm{MeOH} / 1 \mathrm{~N} \mathrm{NaOH} ; 70 \%$ from 18 (e) $\mathrm{NaH}, \mathrm{CS}_{2}, \mathrm{CH}_{3} \mathrm{I}$, THF, reflux, 80\%; (f) $\mathrm{NaBH}_{4} \mathrm{MeOH} / \mathrm{EtOH}=1 / 1,-10{ }^{\circ} \mathrm{C}$; (g) o-xylene, $190{ }^{\circ} \mathrm{C}, 4 \mathrm{~h}, 90 \%$; (h) $\mathrm{MsCl} / \mathrm{Py}$, $0{ }^{\circ} \mathrm{C}, 95 \%$; (i) $\mathrm{AcOH}, 50{ }^{\circ} \mathrm{C}, 95 \%$; (1) $5 \% \mathrm{KOH}(\mathrm{MeOH})$; (m) $\mathrm{PCC} / \mathrm{Al}_{2} \mathrm{O}_{3}, 80 \%$ from 14; (n) $\mathrm{H}_{2} / 10 \%$ $\operatorname{Pd}(\mathrm{C}), 95 \%$.

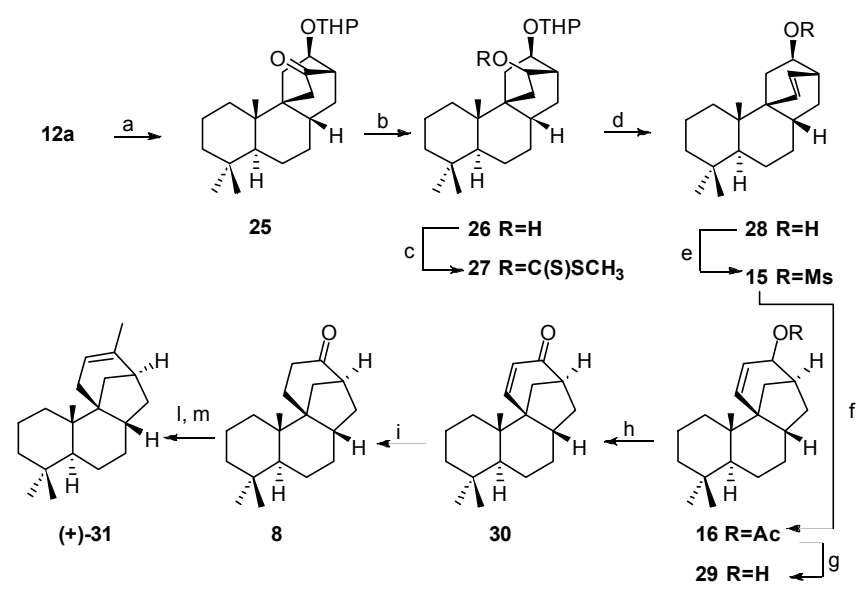

Scheme 4. Synthesis of 17-Norstemodan-16-one. Reagents and conditions: (a) DHP, $\mathrm{TsOH}, \mathrm{CHCl}_{3}, 95 \%$; (b) $\mathrm{NaBH}_{4}, \mathrm{MeOH} / \mathrm{Et}_{2} \mathrm{O}=1 / 1$, quantitative yield; (c) $\mathrm{NaH}, \mathrm{CS}_{2}, \mathrm{CH}_{3} \mathrm{I}$, THF, reflux, 80\%; (d) o-xylene, $190{ }^{\circ} \mathrm{C}, 4 \mathrm{~h}, 85 \%$; (e) $\mathrm{MsCl} / \mathrm{Py}, 0{ }^{\circ} \mathrm{C}, 73 \%$; (f) $\mathrm{AcOH}, 50{ }^{\circ} \mathrm{C}, 95 \%$; (g) $5 \% \mathrm{KOH}(\mathrm{MeOH})$; (h) $\mathrm{PCC} / \mathrm{Al}_{2} \mathrm{O}_{3}$, $80 \%$ from 16; (i) $\mathrm{H}_{2} / 10 \% \mathrm{Pd}(\mathrm{C}), 95 \%$; (l) $\mathrm{CH}_{3} \mathrm{MgI} / \mathrm{Et}_{2} \mathrm{O}$; (m) $\mathrm{POCl}_{3} / \mathrm{Py}$. 
The strategy adopted for the obtaining of tetracyclic ketones 7 and 8, models of 5a and 6 respectively, and the methodologies set-up during the model work, was so efficient that the following year formal total syntheses of $( \pm)-\mathbf{1}$ and $( \pm)-\mathbf{2 a},( \pm)-\mathbf{2 b}$ and total syntheses of $( \pm)-\mathbf{2 c}$ and $( \pm)$-2d were achieved by a very small group of enthusiastic young people $[13,48]$. Later a diastereoselective total synthesis of $( \pm)-\mathbf{1}$ was also described [14].

\section{Synthesis of (+)-Stemod-12-ene, (+)-2-Deoxystemodinone and (+)-Aphidicol-15-ene from (+)-Podocarpic Acid via (-)-9(11)-Podocarpen-12-one (1983-1984)}

During the same time period Professor Ronald B. Kelly, a former co-worker of Professor Wiesner, got interested in the synthesis of aphidicolane, stemodane and stemarane diterpenoids and in 1980 reported with his group at the University of New Brunswick (Saint John, NB, Canada) the first total synthesis of $( \pm)$-stemarin (3a) [49]. In the following years the Kelly group focused its attention on stemodane and aphidicolane diterpenoids. In this frame the syntheses of (+)-stemod-12-ene (31), (+)-2-deoxystemodinone (2d) [50] and (+)-aphidicol-15-ene (36) [51] from (+)-podocarpic acid (4) were achieved.

\subsection{Retrosynthetic Analysis and Strategy}

The approach adopted by Kelly and his group for obtaining (+)-stemod-12-ene (31), and (+)-aphidicol-15-ene (36) was also based on the bicyclo[2.2.2]octane $\rightarrow$ bicyclo[3.2.1]octane skeletal rearrangement (Scheme 5). (+)-Podocarpic acid (4) was also used as starting material. Being (+)-31 and (+)-36 the targets, a methyl group was introduced at C-13 in 17. Its presence would later ensure the completeness of the rearrangement.

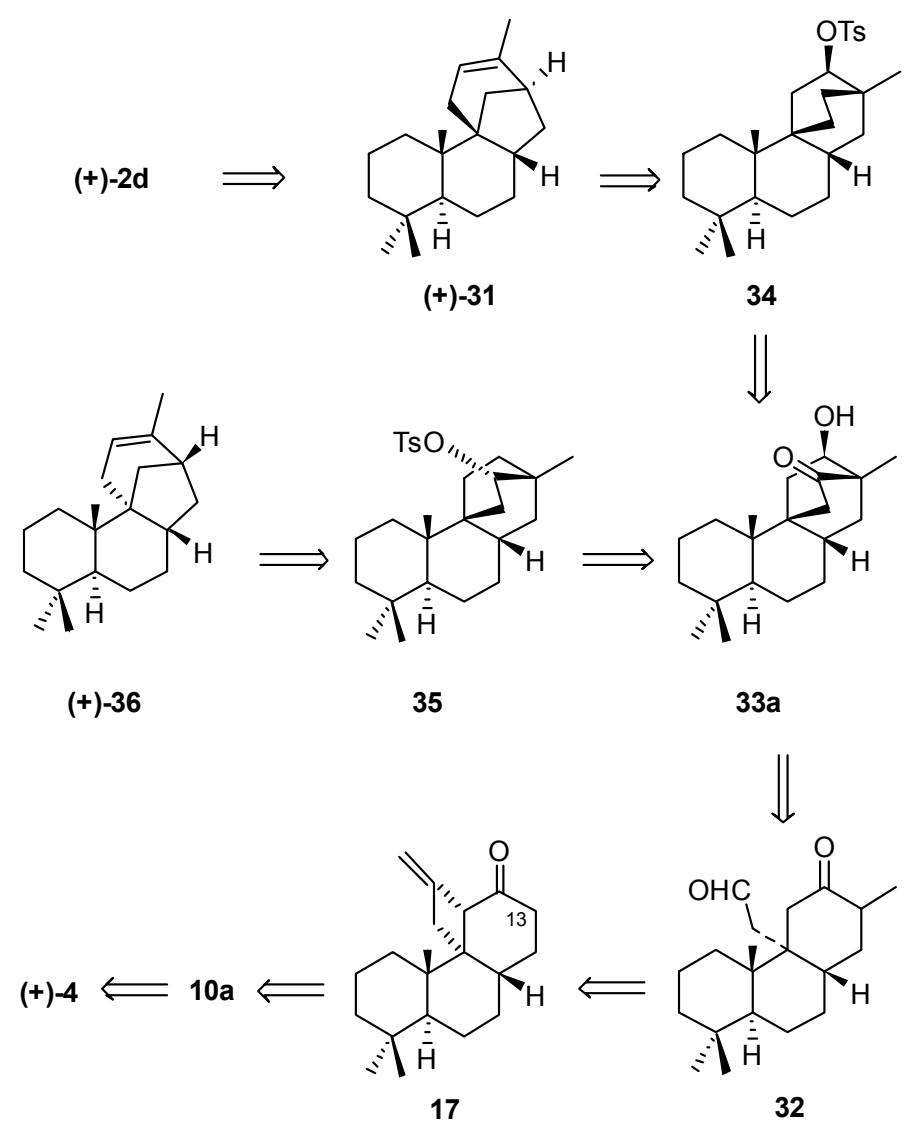

Scheme 5. Retrosynthetic analysis for the obtaining of (+)-31, (+)-2d and (+)-36. 


\subsection{Synthesis of (+)-Stemod-12-ene and (+)-2-Deoxystemodinone (1983)}

The starting material was the photoadduct 17 [47] (vide supra). Methylation at C(13) of the latter gave 37 which was acetalized to 38 by standard methods (Scheme 6). The exocyclic methylene in $\mathbf{3 8}$ was then cleaved to the cyclobutanone 39 and the latter reduced to the cyclobutanol 40 which on refluxing in a THF $/ \mathrm{HCl}$ mixture underwent deacetalization followed by a retro-aldol and an aldol reaction to give 33 as an epimeric mixture at $C(12)$ (see Section 8.1). The major epimer 33a was then converted into the corresponding dithioacetal derivative 41a and the latter desulphurized with Raney-Ni in $\mathrm{EtOH}$ to give 42a. The alcohol 42a was then transformed into the corresponding tosylate $\mathbf{3 4}$ which on heating in DMSO in the presence of the methyl sulfinyl carbanion gave (+)-stemod-12-ene (31) (see Section 8.3). (+)-2-Deoxystemodinone (2d) was eventually obtained from (+)-31 by epoxidation followed by hydride epoxide reduction [50]. The use of (+)-podocarpic acid (4) as starting material also allowed confirmation of the absolute configuration attributed to the stemodane diterpenoids on the basis of ORD and CD studies.

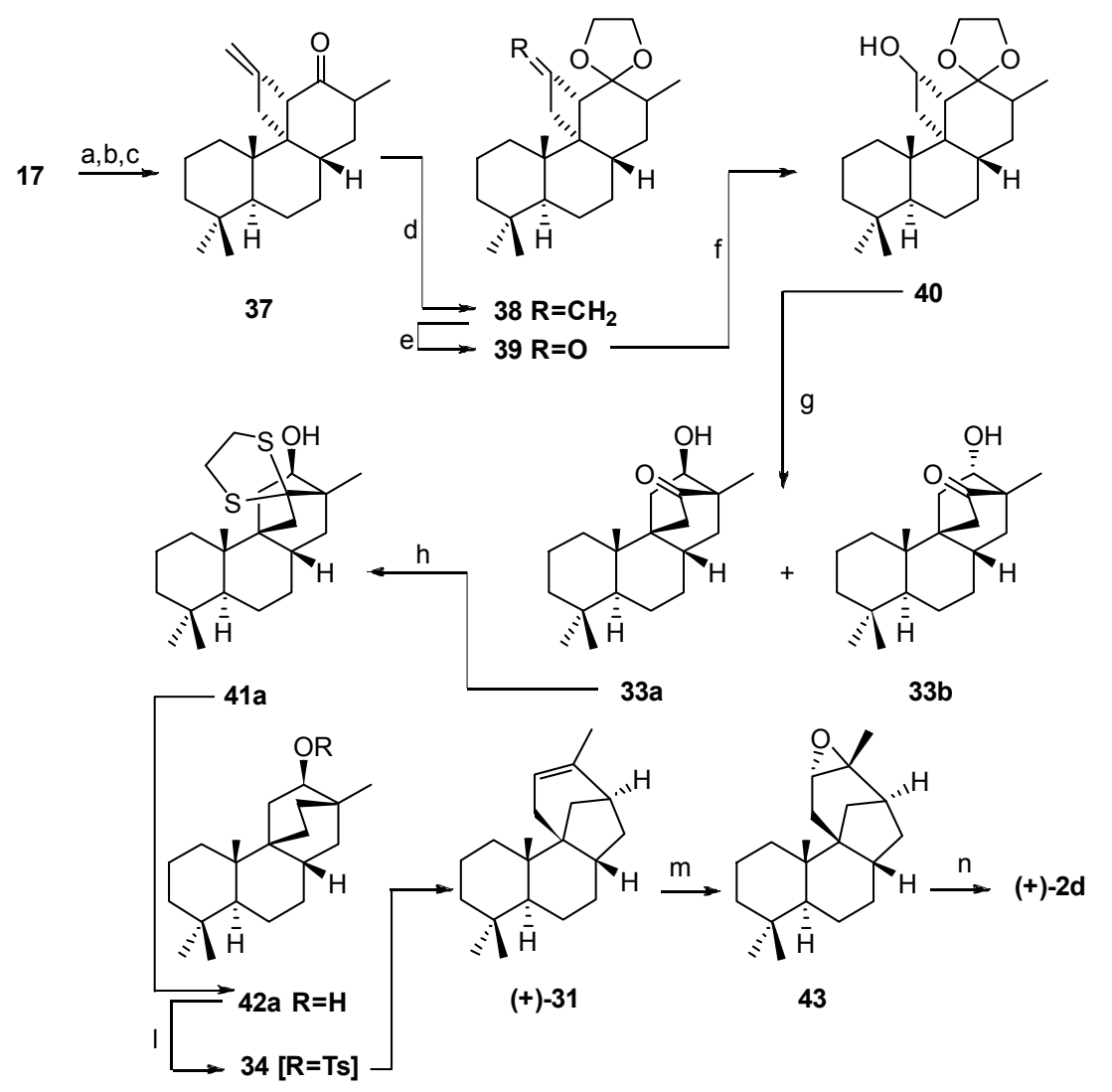

Scheme 6. Synthesis of (+)-Stemod-12-ene and (+)-2-Deoxystemodinone. Reagents and conditions: (a) $\mathrm{NaH}, \mathrm{CO}\left(\mathrm{OCH}_{3}\right)_{2}, 97 \%$; (b) $\mathrm{NaH}, \mathrm{MeI}, 90 \%$; (c) $10 \% \mathrm{KOH} / \mathrm{EtOH}$, reflux, 89\%; (d) ethylene glycol, $\mathrm{TsOH}$, toluene, Dean-Stark, reflux, $87 \%$; (e) $\mathrm{OsO}_{4}$, dioxane $/ \mathrm{Py} / \mathrm{H}_{2} \mathrm{O} / \mathrm{NaIO}_{4}, 77 \%$; (f) $\mathrm{NaBH}_{4}, \mathrm{EtOH}$, $\mathrm{Et}_{2} \mathrm{O}, 99 \%$; (g) $1 \mathrm{~N} \mathrm{HCl}$, THF, reflux, 76\%; (h) 1,2-ethanedithiol, $\mathrm{BF}_{3} \cdot \mathrm{Et}_{2} \mathrm{O}, 0{ }^{\circ} \mathrm{C}, 85 \%$; (i) Raney-Ni/EtOH, 83\%; (1) TsCl/Py, 70\%; (m) m-chloroperbenzoic acid, benzene, 75\%; (n) $\mathrm{LiAlH}_{4}, \mathrm{Et}_{2} \mathrm{O}, 75 \%$.

\subsection{Synthesis of (+)-Aphidicol-15-ene (1984)}

The starting material was 33a (Scheme 7) which was converted into the dithiocarbonate 44. The latter, upon reduction with $\mathrm{NaBH}_{4}$ gave diastereoselectively the alcohol 45 which was transformed into the benzoate 46 . Reduction of the latter with tri- $n$-butyltin hydride followed by saponification gave 47. The conversion of 47 into (+)-36 [51] paralleled that of 42a into (+)-31 [50] (see Section 8.4). 


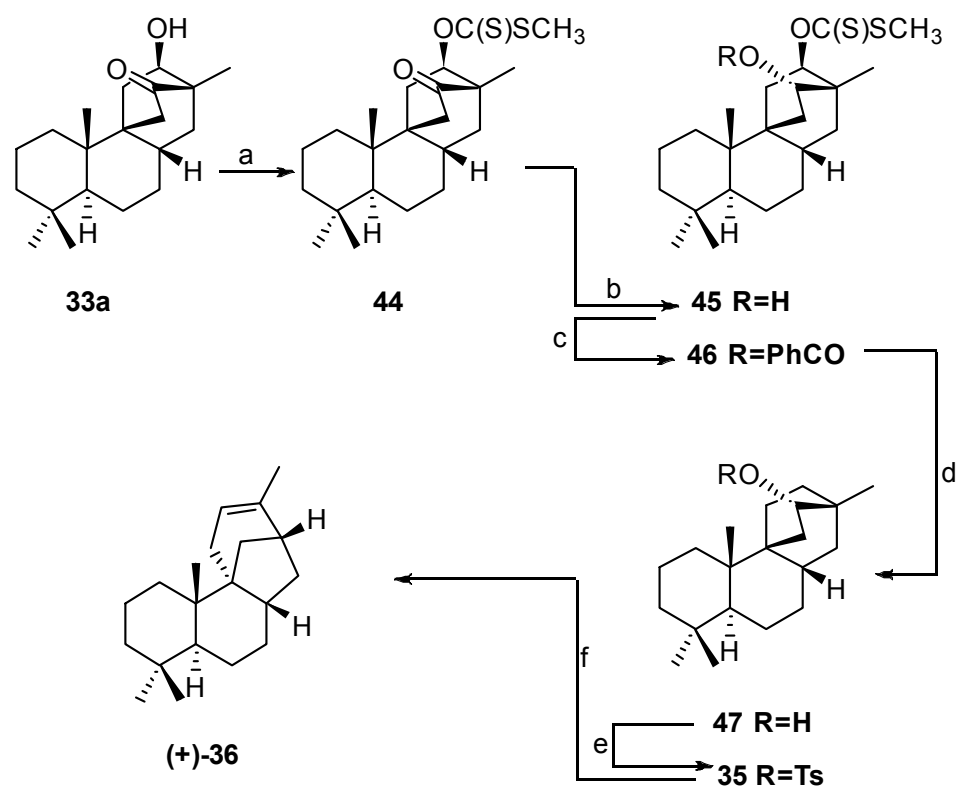

Scheme 7. Synthesis of (+)-Aphidicol-15-ene. Reagents and conditions: (a) NaH, imidazole, THF, $\mathrm{CS}_{2}$, $\mathrm{CH}_{3} \mathrm{I}, 87 \%$; (b) $\mathrm{MeOH} / \mathrm{Et}_{2} \mathrm{O}=1 / 1, \mathrm{NaBH}_{4},-10{ }^{\circ} \mathrm{C}, 90 \%$; (c) $\mathrm{PhCOCl} / \mathrm{Py}, 97 \%$; (d) $\mathrm{Bu}_{3} \mathrm{SnH}$, toluene, reflux, $75 \%$; (e) TsCl/Py, $3{ }^{\circ} \mathrm{C}, 72 \mathrm{~h}, 60 \%$; (f) $\mathrm{CH}_{3} \mathrm{~S}(\mathrm{O}) \mathrm{CH}_{2}{ }^{-} \mathrm{Na}^{+} / \mathrm{CH}_{3} \mathrm{~S}(\mathrm{O}) \mathrm{CH}_{3}, 60{ }^{\circ} \mathrm{C}, 2 \mathrm{~h}, 60 \%$.

\section{Proof of the Structure of the Stemodia chilensis Tetracyclic Diterpenoid (+)-19-Acetoxy-stemodan-12-ol by Synthesis from (+)-Podocarpic Acid (2016)}

The aim of this work was to confirm the structure of (+)-19-acetoxystemodan-12-ol (2f) isolated in 1991 from Stemodia chilensis [52]. The structure of this diterpenoid had been established only on the basis of ${ }^{1} \mathrm{H}$ - and ${ }^{13} \mathrm{C}-\mathrm{NMR}$ spectroscopic data and on their similarity with those of co-occurring (+)-2-deoxystemodinone (2d). The starting material was compound (+)-48, obtained from (+)-podocarpic acid (4) as previously described (see Section 7). The strategy adopted is that described in Scheme 5. The HO-C(12) in (+)-48 is properly oriented for rearrangement to the stemodane system. Nevertheless, prior to rearrangement it was necessary to remove the $C(15)$ carbonyl group, which would have prevented the rearrangement to the stemodane system by inhibiting the formation of a positive charge on the adjacent bridgehead carbon, and to convert the $\mathrm{HO}-\mathrm{C}(12)$ into a better leaving group after selective protection of the HO-C(19).

Compound (+)-48 (Scheme 8) was therefore converted by standard methods into the corresponding dithioacetal (+)-49 which was chemoselectively acetylated to give (+)-50. Desulphurization of the latter gave (-)-51, which was treated with $\mathrm{MsCl}$ in pyridine to afford, via 52, (+)-19-acetoxystemod-12-ene (53) (see Section 8.3). Compound (+)-53, whose relative configuration was confirmed by an X-ray structure determination, was then stereoselectively epoxidized to (+)-54. The epoxidation of the stemod-12-ene system proceeds, in fact, from the less hindered $\alpha$ face [50]. Reduction of (+)-54 with $\mathrm{LiAlH}_{4}$ gave then the diol 2e which was then acetylated to (+)-2f [53]. The identity of (+)-2f with the diterpenoid isolated from Stemodia chilensis was confirmed by comparing the NMR data. Remarkably in this synthesis all chiral centers present in (+)-podocarpic acid (4) are maintained. 

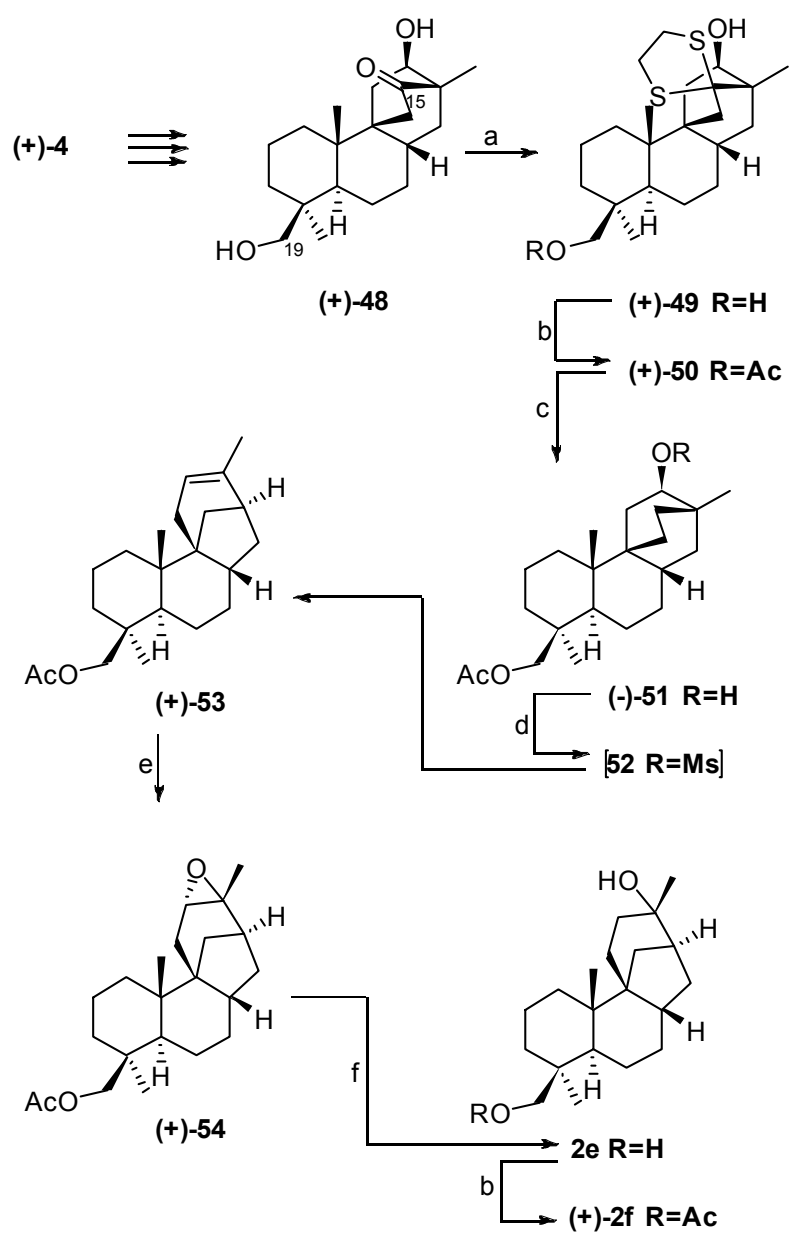

Scheme 8. Synthesis of (+)-19-Acetoxy-stemodan-12-ol. Reagents and conditions: (a) 1,2-ethanedithiol, $\mathrm{BF}_{3} \cdot \mathrm{Et}_{2} \mathrm{O}, 0{ }^{\circ} \mathrm{C}, 59 \%$; (b) 2,6-lutidine, $\mathrm{AcCl}, \mathrm{CH}_{2} \mathrm{Cl}_{2}, \mathrm{rt}, 83 \%$; (c) Raney-Ni, $\mathrm{EtOH}, 60{ }^{\circ} \mathrm{C}, 80 \%$; (d) $\mathrm{MsCl}$, $\mathrm{NEt}_{3}, \mathrm{CH}_{2} \mathrm{Cl}_{2}$, rt, 66\%; (e) $m$-chloroperbenzoic acid, $\mathrm{CH}_{2} \mathrm{Cl}_{2}, 89 \%$; (f) $\mathrm{LiAlH}_{4}, \mathrm{Et}_{2} \mathrm{O}, 40 \%$.

\section{Synthesis of (+)-Stemar-13-ene, (+)-18-Deoxystemarin from (+)-Podocarpic Acid via 9(11)-Podocarpen-12-one (1991-2012)}

After the successful conclusion of the work on aphidicolane and stemodane diterpenoids, $( \pm$ )-stemarin (3a) became the target of our studies. This tetracyclic diterpenoid had been synthesized in racemic form by Kelly and co-workers in 1980 [49]. Unfortunately this synthesis suffered a non-diastereoselective step, i.e., the completion of the synthesis with the minor epimer produced by the aldol condensation by which the bicyclo[2.2.2]octane system was formed. Developing a diastereoselective route to the key 6-hydroxy-1-methylbicyclo[2.2.2]octane intermediate appeared to us a worthwhile synthetic challenge. As it will be seen in the sequel this synthetic problem engaged us for twenty years until a simple solution was found. Being the synthetic problem confined in the construction of the C/D ring system, (+)-stemar-13-ene (57) and (+)-18-deoxystemarin (3b) the simplest compounds in the class were chosen as targets.

\subsection{Retrosynthetic Analysis and Strategy}

The first approach evaluated was based on the inversion of configuration at $\mathrm{C}(12)$ of suitable derivatives of the 13-methyl-12-endo-hydroxybicyclo[2.2.2]octan-15-one intermediate. Intermediates of type 55 were considered suitable to this task owing to the presence of the carbonyl group at $C(15)$ which preventing the formation of a positive charge on the adjacent bridgehead carbon does not allow the rearrangement (Scheme 9). 


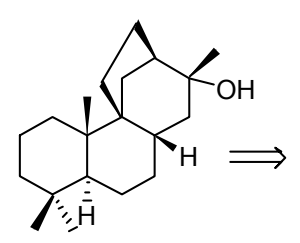

$(+)-3 b$<smiles></smiles>

(+)-57

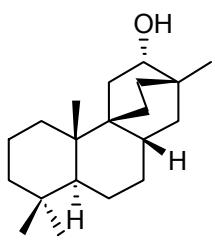

42b

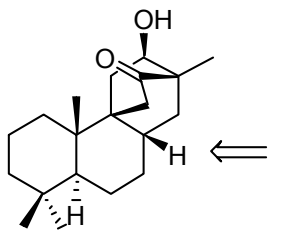

33a

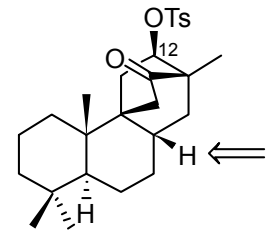

55

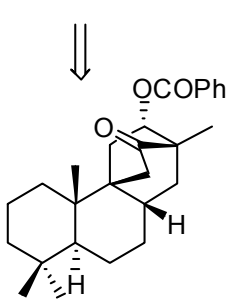

56

Scheme 9. Retrosynthetic analysis for the obtaining of (+)-stemar-13-ene (57) and (+)-18-deoxystemarin (3b).

5.2. Diastereoselective Synthesis of (+)-Stemar-13-ene and (+)-18-Deoxystemarin by Inversion of Configuration at C(12) of Suitable Derivatives of the 13-Methyl-12-endo-hydroxybicyclo[2.2.2]octan-15-one Intermediate (1991)

The starting material was known 33a (vide supra) which was converted [54] into the corresponding tosylate 55 (Scheme 10). The latter was then treated with $\mathrm{Et}_{4} \mathrm{~N}(\mathrm{PhCOO})$ in acetone at reflux affording the exo-benzoate 56. Later the same conversion was performed in benzene resulting in drastically reduced reaction times [55]. This methodology, described in the past for the inversion of configuration of acyclic secondary alcohols [56], was particularly suitable to our case in that it produces a locked exo-ketol which cannot therefore re-equilibrate to the more stable endo epimer.

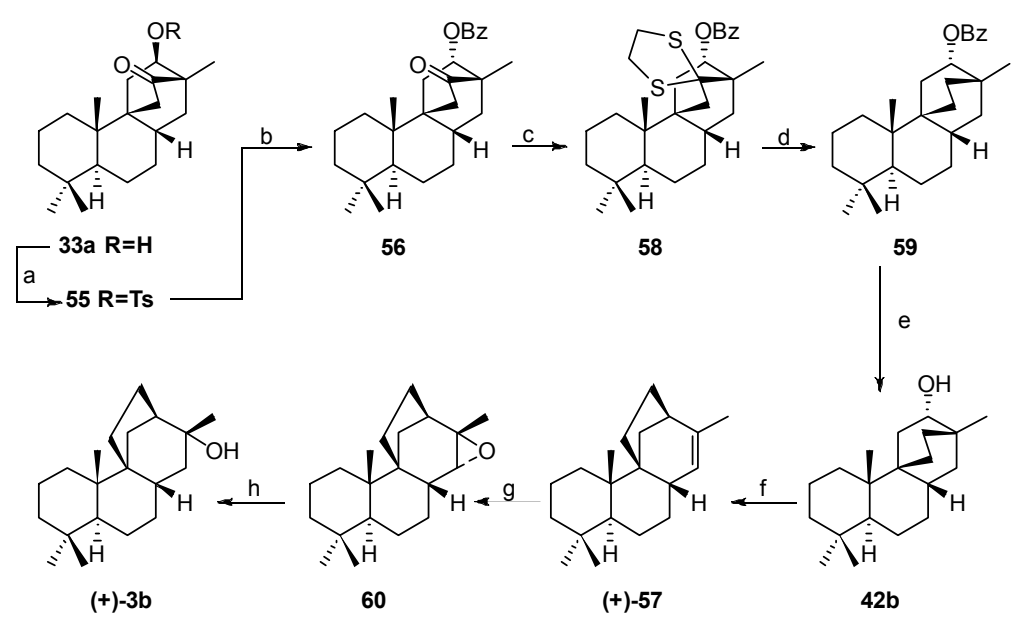

Scheme 10. Synthesis of (+)-Stemar-13-ene and (+)-18-Deoxystemarin. Reagents and conditions: (a) $\mathrm{TsCl} / \mathrm{Py}$; (b) $\mathrm{Et}_{4} \mathrm{~N}(\mathrm{PhCOO}), \mathrm{CO}\left(\mathrm{CH}_{3}\right)_{2}$, reflux; (c) 1,2-ethanedithiol, $\mathrm{BF}_{3} \cdot \mathrm{Et}_{2} \mathrm{O}$; (d) Raney-Ni, $\mathrm{EtOH}$, reflux; (e) $\mathrm{LiAlH}_{4} / \mathrm{THF}$; (f) $\mathrm{TsOH}, \mathrm{C}_{6} \mathrm{H}_{6}$, reflux; (g) $m$-chloroperbenzoic acid, $\mathrm{CH}_{2} \mathrm{Cl}_{2} ;$ (h) $\mathrm{LiAlH}_{4}, \mathrm{Et}_{2} \mathrm{O}$.

Deoxygenation of 56 via 58 by standard methods gave the benzoate 59. Debenzoylation of the latter produced $\mathbf{4 2 b}$ whose $\mathrm{HO}-\mathrm{C}(12)$ is properly oriented for the rearrangement to the stemarane system. Thus refluxing the latter in benzene in the presence of $\mathrm{TsOH}$ gave (+)-stemar-13-ene (57) (see Section 8.5). Finally, epoxidation of the latter followed by $\mathrm{LiAlH}_{4}$ epoxide ring opening gave (+)-3b [54]. This synthesis was accomplished in 1991. In 2001 (+)-stemar-13-ene (57) was isolated from the fungus Phoma betae [57]. The two materials were identical in all respects. 
Later, in view of a methodology [58] by which esters are cleaved in the presence $\mathrm{CH}_{3} \mathrm{ONa} / \mathrm{La}(\mathrm{OTf})_{3}$ at neutral $\mathrm{pH}$, thus ensuring no epimerization at $\mathrm{HO}-\mathrm{C}(12)$, the desulphurization/debenzoylation steps could be reversed [59].

5.3. Synthesis of (+)-Stemar-13-ene and (+)-18-Deoxystemarin: Expeditious Preparation of the Key 13-Methyl-12-exo-hydroxybicyclo[2.2.2]octan-15-one Ethylene Dithioacetal (2008)

Another approach considered for a diastereoselective route to the key 13-methyl-12hydroxybicyclo[2.2.2]octanols of the type of $42 \mathrm{~b}$ concerned the possibility of obtaining ethylene dithioacetals of the type of $\mathbf{6 2}$ and $\mathbf{4 1 b}$ by equilibration under acidic conditions (b in Scheme 11).

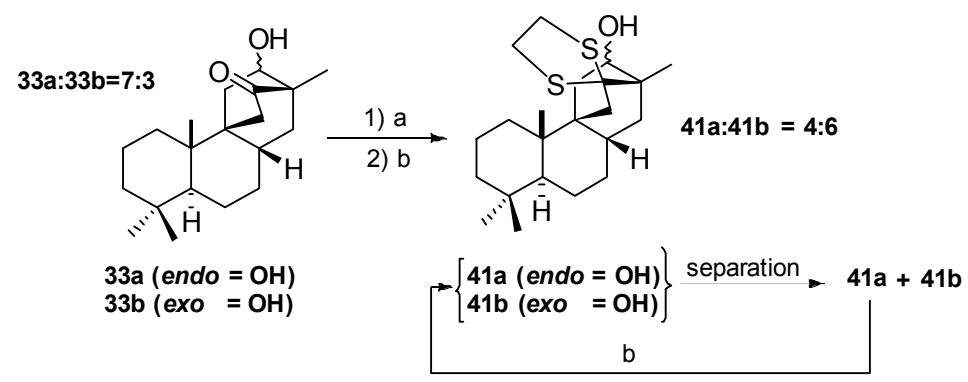

Scheme 11. Equilibration under acidic condition of hydroxydithioacetals 41. Reagents and conditions:

(a) 1,2-ethanedithiol, $\mathrm{BF}_{3} \cdot \mathrm{Et}_{2} \mathrm{O}$, rt.; (b) $\mathrm{TsOH}$, benzene, reflux.

Compounds 62 and $41 \mathrm{~b}$ (Figure 3) can be efficiently prepared by thioacetalization with 1,2-ethanedithiol in the presence of $\mathrm{BF}_{3} \cdot \mathrm{Et}_{2} \mathrm{O}$ from the corresponding 13-methyl-12-exo-hydroxybicyclo [2.2.2] octan-15-ones $\mathbf{6 1}$ and $\mathbf{3 3 b}$ respectively.

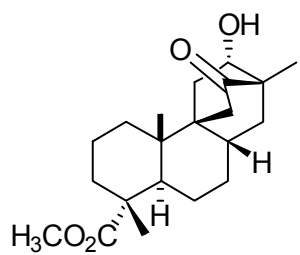

61

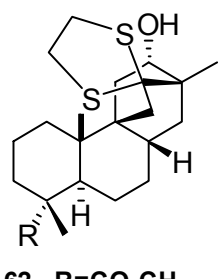

$62 \mathrm{R}=\mathrm{CO}_{2} \mathrm{CH}_{3}$ 41b $\mathrm{R}=\mathrm{CH}_{3}$

Figure 3. Key exo-Hydroxybicyclo[2.2.2]octane Ethylene Dithioacetals.

Thus a 7:3 endo/exo mixture of hydroxydithioacetals 41 , prepared from 33 by the action of 1,2-ethanedithiol in the presence of $\mathrm{BF}_{3} \mathrm{Et}_{2} \mathrm{O}$, was submitted to equilibration with $\mathrm{TsOH}$ in benzene. The equilibrium endo/exo ratio resulted 4:6. Hydroxydithioacetals $41 \mathrm{a}$ and $\mathbf{4 1} \mathbf{b}$ could be separated by HPLC. By repeating three times the equilibration/separation cycle, practically all the material $(94 \%)$ could be converted into the desired exo epimer 41b [60].

6. Regio- and Diastereoselective Synthesis of (+)-Stemar-13-ene and (+)-18-Deoxystemarin by the 6-Hydroxy-1-methylbicyclo[2.2.2] octan-2-one $\rightarrow$ 4-Methylbicyclo[3.2.1]oct-3-en-6-one Skeletal Rearrangement (2011)

\subsection{Retrosynthetic Analysis and Strategy}

Finally, a new, general and simple solution for the construction of the stemarane diterpene $\mathrm{C} / \mathrm{D}$ ring system was found. This solution is based on the existing endo/exo equilibrium under acidic conditions between 1-methyl-6-hydroxybicyclo[2.2.2]octan-2-ones (Scheme 12a) and on the acid catalyzed rearrangement of 1-methyl-6-hydroxybicyclo[2.2.2]octan-2-ones to 4-methylbicyclo [3.2.1] oct-3-en-6-ones (Scheme 12b) described in 2005 within the framework of a study on the reactivity of isotwistanes [61]. 
a)

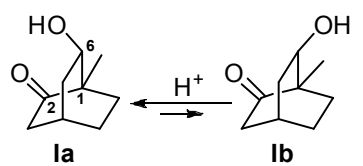

b)

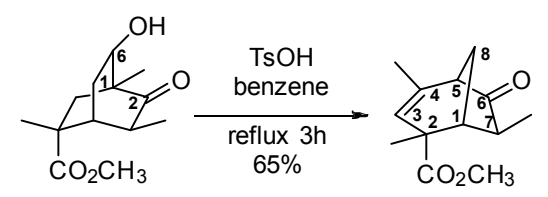

II

III

Scheme 12. (a) endo/exo 1-methyl-6-hydroxybicyclo[2.2.2]octan-2-ones equilibrium under acidic conditions; (b) TsOH promoted rearrangement of 1-methyl-6-hydroxybicyclo[2.2.2]octan-2-ones to 4-methyl-bicyclo[3.2.1]oct-3-en-6-ones.

The following retrosynthetic analysis therefore resulted (Scheme 13).

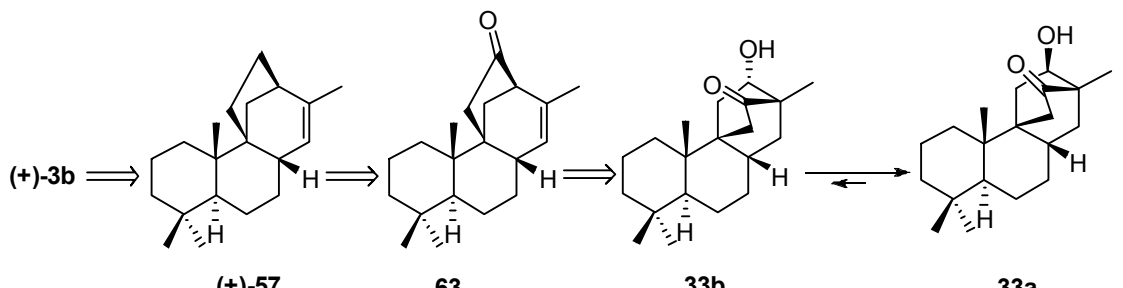

$(+)-57 \quad 63$

33b

33a

Scheme 13. Retrosynthetic analysis for obtaining (+)-57 and (+)-3b by $\mathrm{TsOH}$ promoted rearrangement of $33 \mathrm{~b}$.

\subsection{Synthesis of (+)-Stemar-13-ene}

Thus the 85:15 endo/exo mixture 33, was dissolved in toluene and heated at $85{ }^{\circ} \mathrm{C}$ in the presence of $\mathrm{TsOH}$ (Scheme 14). After $24 \mathrm{~h}$ the rearrangement of 33 to (+)-63 was completed (see Section 8.6). Thioacetalization of (+)-63 by standard procedures afforded then (+)-64 which was desulphurized to $(+)-57[55,62]$.

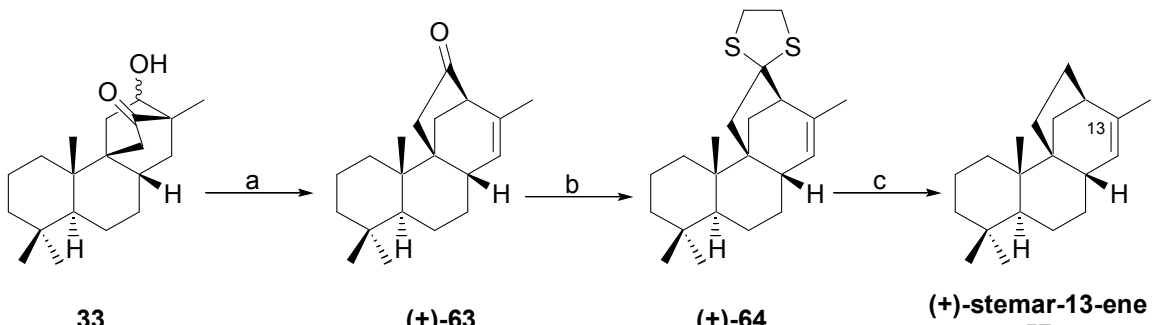

33

$(+)-63$

$(+)-64$

57

Scheme 14. Synthesis of (+)-Stemar-13-ene (57) by TsOH promoted rearrangement of 33. Reagents and conditions: (a) TsOH, toluene, reflux; (b) 1,2-ethanedithiol, $\mathrm{BF}_{3} \cdot \mathrm{Et}_{2} \mathrm{O}, 0{ }^{\circ} \mathrm{C}, 85 \%$; (c) Raney-Ni, $\mathrm{EtOH}$, $60{ }^{\circ} \mathrm{C}, 76 \%$.

The remarkable feature of this approach is that, owing to the stereospecificity of the rearrangement and to the 1-methyl-6-hydroxybicyclo[2.2.2]octan-2-ones endo/exo equilibrium, the whole endo/exo mixture 33 is converted into the rearrangement product in which the $\mathrm{C}(13)-\mathrm{C}(14)$ double bond is also present, a characteristic feature of some stemarane diterpenoids such as (+)-oryzalexin $\mathrm{S}(\mathbf{6 5})$ (Figure 4) $[63,64]$ (induced in rice leaves in response to the invasion of the fungus Pyricularia oryzae or when exposed to UV radiation or heavy metals [65]) and a necessary tool for the introduction of the $\alpha$-configured $\mathrm{HO}-\mathrm{C}(13)$ if necessary. 


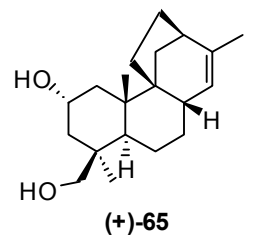

Figure 4. (+)-oryzalexin S.

\section{Regio- and Diastereoselective Synthesis of (+)-2-Deoxyoryzalexin S from (+)-Podocarpic Acid (2012)}

Finally, having in hand an efficient methodology for the construction of the C/D ring system of stemarane diterpenoids, we decided to apply it to the synthesis of (+)-2-deoxyoryzalexin $S$ (66), the structure and absolute configuration of which had been established only on the basis of the corresponding ${ }^{1} \mathrm{H}$ - and ${ }^{13} \mathrm{C}-\mathrm{NMR}$ spectra [66-68]. The strategy adopted is that described in Scheme 13. The starting material was (-)-19-hydroxypodocarp-9-en-12-one (67), available in four steps from (+)-podocarpic acid (4). Photoaddition of allene to (-)-67 in THF at $-78{ }^{\circ} \mathrm{C}$ gave quantitatively the photoadduct (+)-68 the structure of which was established by 2D NMR experiments (Scheme 15). Prior to methylation at C(13), the HO-C(19) in (+)-68 was protected to give (+)-69. Compound (+)-69 was then methylated to give $\mathbf{7 0}$. The latter was then converted into the acetal $\mathbf{7 1}$, and the exocyclic methylene cleaved with $\mathrm{OsO}_{4} / \mathrm{NaIO}_{4}$ to give the cyclobutanone 72 along with some unprotected keto-alcohol 73. Compound $\mathbf{7 2}$ was then reduced to the cyclobutanol 74. Treatment of $\mathbf{7 4}$ with a 2:1 $\mathrm{THF} / 2 \mathrm{~N} \mathrm{HCl}$ mixture gave 48 as an about 80:20 endo/exo C(12) epimeric mixture (see Section 8.1). The latter dissolved in toluene was heated at $85{ }^{\circ} \mathrm{C}$ in the presence of $\mathrm{TsOH}$, giving (+)-77 (see Section 8.6$)$. Thioacetalization of (+)-77 by standard methods followed by deoxygenation gave then (+)-2-deoxyoryzalexin $S$ (66) which was then acetylated to (+)-79 [69].

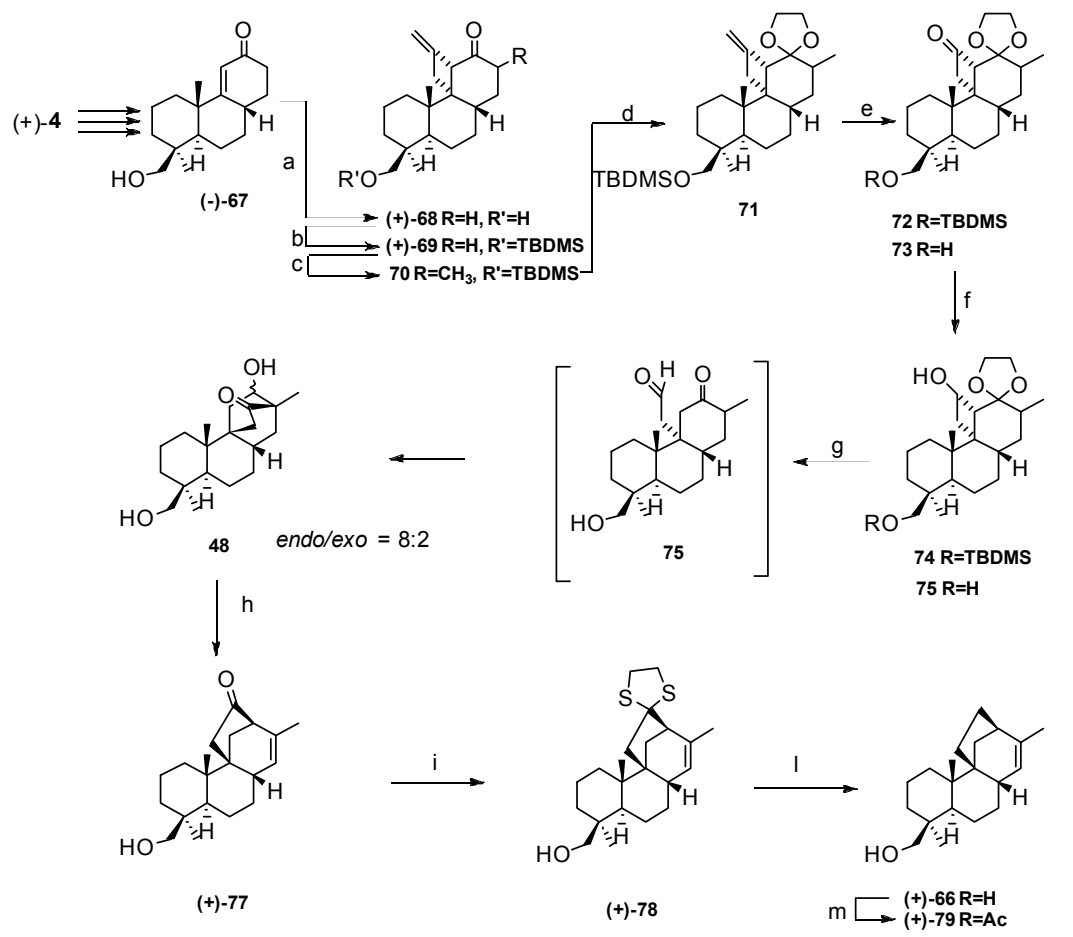

Scheme 15. Regio- and Diastereoselective Synthesis of (+)-2-Deoxyoryzalexin S. Reagents and conditions: (a) allene, THF, $-78{ }^{\circ} \mathrm{C}$, hv, $81 \%$; (b) TBDMSCl, imidazole, THF, $89 \%$; (c) $\mathrm{NaHDMS}, \mathrm{CH}_{3} \mathrm{I}, \mathrm{THF},-78^{\circ} \mathrm{C}$; (d) ethylene glycol, toluene, $\mathrm{TsOH} 78 \%$; (e) $\mathrm{OsO}_{4} / \mathrm{NaIO}_{4}, \mathrm{THF}, \mathrm{H}_{2} \mathrm{O}$; (f) $\mathrm{NaBH}_{4}, \mathrm{EtOH} / \mathrm{MeOH}, 0{ }^{\circ} \mathrm{C}$; (g) $\mathrm{THF} / 2 \mathrm{~N} \mathrm{HCl}, 88 \%$; (h) $\mathrm{TsOH}$, benzene, $85{ }^{\circ} \mathrm{C}$, $66 \%$; (i) 1,2-ethanedithiol, $\mathrm{BF}_{3} \cdot \mathrm{Et}_{2} \mathrm{O}, 0{ }^{\circ} \mathrm{C}, 84 \%$; (l) Raney-Ni, $\mathrm{EtOH}, 60{ }^{\circ} \mathrm{C}, 62 \%$; (m) $\mathrm{Ac}_{2} \mathrm{O} / \mathrm{Py}, 99 \%$. 
The relative configuration of (+)-79 was confirmed by an X-ray structure determination. This work allowed also to demonstrate that the structure of (+)-2-deoxyoryzalexin $S(66)$ could be not attributed to a Chilean Calceolaria isolated diterpenoid to which this structure had been assigned. Remarkably also in this synthesis all chiral centers present in (+)-podocarpic acid (4) are maintained.

\section{Main Skeletal Rearrangements: Mechanistic Aspects}

8.1. Conversion of Cyclobutanols 19, 40, 74 (and 75) into Hydroxybicyclo[2.2.2]octanones 12, 33, and 48, Respectively

Deprotection of the carbonyl function under acidic conditions unmasks a 1,3-hydroxyketone function which undergoes first a retro-aldol reaction then a new aldol reaction leading to the products (Scheme 16).

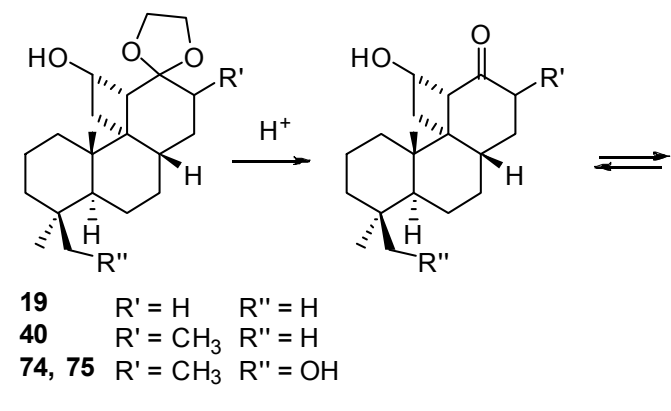

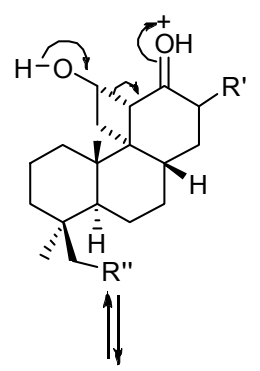

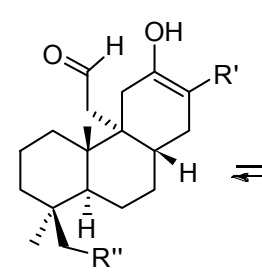

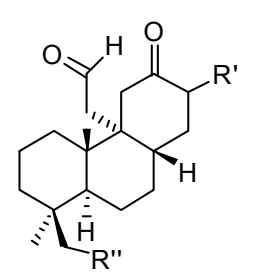

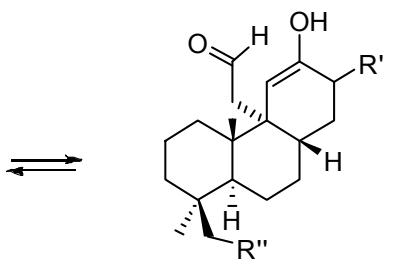

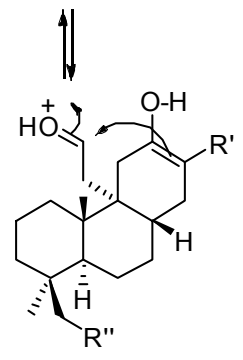

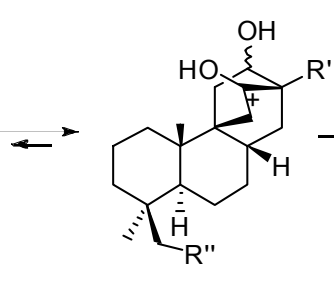

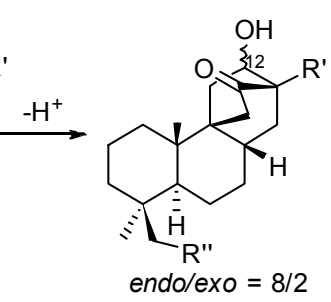

$12 R^{\prime}=H \quad R^{\prime \prime}=H$

$33 \mathrm{R}^{\prime}=\mathrm{CH}_{3} \mathrm{R}^{\prime \prime}=\mathrm{H}$

$48 \mathrm{R}^{\prime}=\mathrm{CH}_{3} \mathrm{R}^{\prime \prime}=\mathrm{OH}$

Scheme 16. Conversion of Cyclobutanols 19, 40, 74 (and 75) into Hydroxybicyclo[2.2.2]octanones 12, 33 , and 48 , respectively.

\subsection{Skeletal Rearrangements of Mesylates 13 and $\mathbf{1 5}$ into Allylic Acetates $\mathbf{1 4}$ and 16, Respectively}

The presence of a double bond endo to the leaving group ensures a quantitative rearrangement by stabilizing the positive charge on the former bridgehead carbon (Scheme 17). 
a)

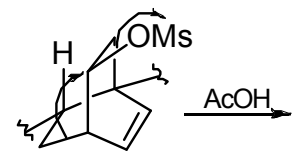

13<smiles>C1=CC2(CCCC2)CC2CCC1C2</smiles>

$+1 \equiv \zeta$

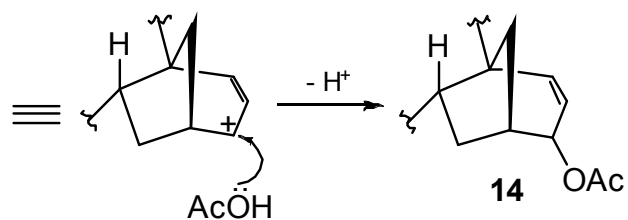

b)

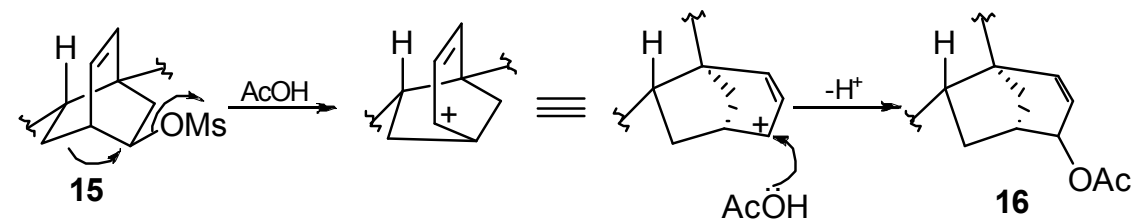

Scheme 17. Skeletal Rearrangements of Mesylates 13 (a) and 15 (b) into Allylic Acetates 14 and 16, respectively.

\subsection{Skeletal Rearrangements of Compounds 34 and 52 into 31 and 53, Respectively}

The presence of a methyl group on the bridgehead carbon ensures a quantitative rearrangement by stabilizing the positive charge on the former bridgehead carbon (Scheme 18).

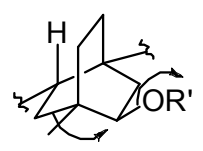

$34 \mathrm{R}^{\prime}=\mathrm{Ts}$

$52 \mathrm{R}^{\prime}=\mathrm{Ms}$

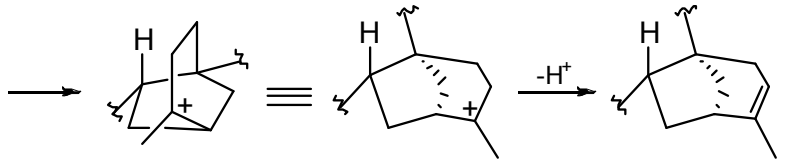

31

53

Scheme 18. Skeletal Rearrangements of Compounds 34 and 52 into 31 and 53, respectively.

\subsection{Skeletal Rearrangement of Tosylate 35 into 36}

The presence of a methyl group on the bridgehead carbon ensures a quantitative rearrangement by stabilizing the positive charge on the former bridgehead carbon (Scheme 19).

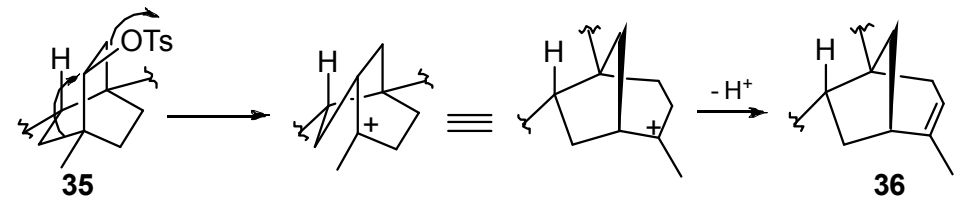

Scheme 19. Skeletal Rearrangement of Tosylate 35 into 36.

\subsection{Skeletal Rearrangement of $\mathbf{4 2 b}$ into $\mathbf{5 7}$}

The presence of a methyl group on the bridgehead carbon ensures a quantitative rearrangement by stabilizing the positive charge on the former bridgehead carbon (Scheme 20).

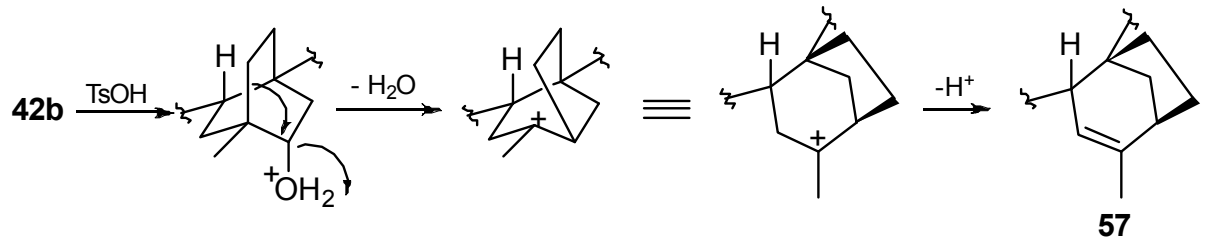

Scheme 20. Skeletal Rearrangement of $42 b$ into 57. 


\subsection{Skeletal Rearrangements of 33 and 48 into 63 and 77, Respectively}

The presence of a methyl group on the bridgehead carbon ensures a quantitative rearrangement by stabilizing the positive charge on the former bridgehead carbon (Scheme 21).

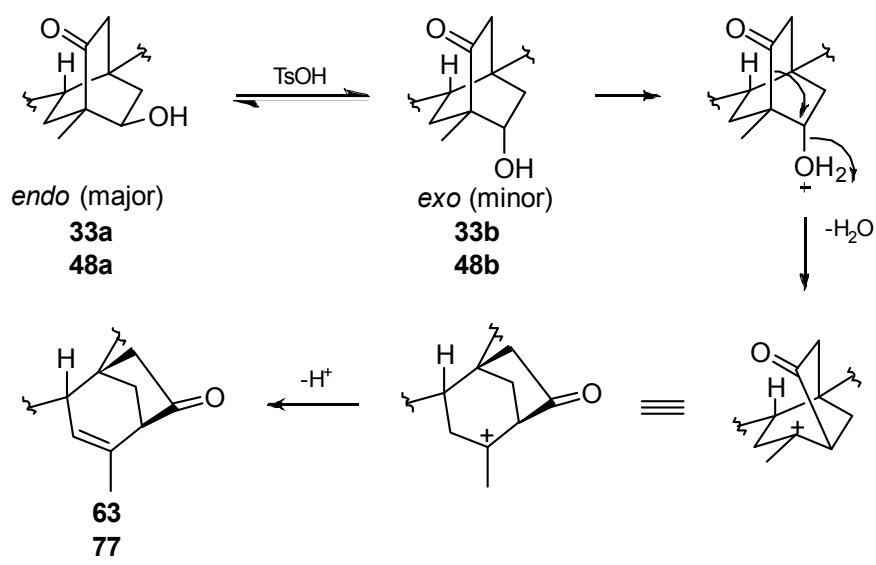

Scheme 21. Skeletal Rearrangements of 33 and 48 into 63 and 77, respectively.

The alternative rearrangement cannot occur owing to the presence of the carbonyl group at $C(12)$ which prevents the formation of a positive charge on the adjacent bridgehead carbon (Scheme 22).

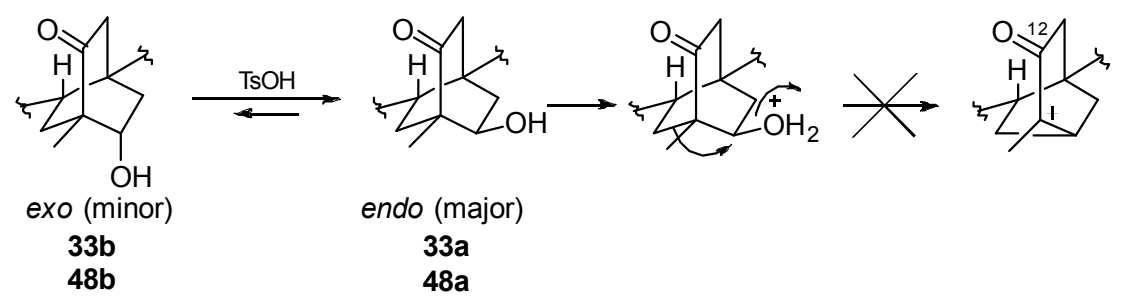

Scheme 22. Role of the carbonyl in preventing the rearrangement of 33a and 48a.

\section{Conclusions}

In this paper the use of (+)-podocarpic acid (4) as starting material for the synthesis of aphidicolane, stemodane and stemarane diterpenoids has been reviewed. As it could be seen (+)-podocarpic acid (4) was a very useful tool in a model study leading to the syntheses of tetracyclic ketones 7 and 8 , models of aphidicolin and stemodin syntheses key intermediates $5 \mathbf{a}$ and $\mathbf{6}$ respectively [47]. (+)-Podocarpic acid (4) was then used for obtaining (+)-stemod-12-ene (31) and (+)-2-deoxystemodinone (2d), thus confirming the absolute configuration attributed to the stemodane diterpenoids on the basis of ORD and CD studies [50]. (+)-Podocarpic acid (4) was also converted into (+)-aphidicol-15-ene (36) [51] and into the Stemodia chilensis tetracyclic diterpenoid (+)-19-acetoxystemodan-12-ol (2f) allowing confirmation of the structure attributed to the latter only on the basis of NMR experiments [54]. $(+)$-Podocarpic acid (4) was then extensively used in the work which led to the synthesis of $(+)$-stemar-13-ene (57) and (+)-18-deoxystemarin (3b) [55,56,59,60,62]. (+)-Podocarpic acid (4) was also converted into (+)-2-deoxyoryzalexin $S$ (66) [69]. The latter work also allowed us to demonstrate that the structure of (+)-2-deoxyoryzalexin S (66) cannot be attributed to a Chilean Calceolaria isolated diterpenoid. Finally, in view of its chemical transformations [70], (+)-podocarpic acid might represent a valuable starting material for the synthesis of $(+)$-aphidicolin $(\mathbf{1}),(+)$-stemodin $(\mathbf{2 a})$ and $(+)$-stemarin (3a) analogues. 
Acknowledgments: Financial support over the years to our work described in this review from the Italian National Research Council (CNR), the Public Education Ministry and the University of Rome "La Sapienza" is gratefully acknowledged.

Conflicts of Interest: The authors declare no conflict of interest.

\section{References}

1. Brundret, K.M.; Dalziel, W.; Hesp, B.; Jarvis, J.A.J.; Neidle, S. X-ray crystallographic determination of the structure of the antibiotic aphidicolin: A tetracyclic diterpenoid containing a new ring system. J. Chem. Soc. Chem. Commun. 1972, 18, 1027-1028. [CrossRef]

2. Dalziel, W.; Hesp, B.; Stevenson, K.M.; Jarvis, J.A.J. The Structure and Absolute Configuration of the Antibiotic Aphidicolin: A Tetracyclic Diterpenoid Containing a New Ring System. Chem. Soc. Perkin Trans. 1 1973, 2841-2851. [CrossRef]

3. Manchand, P.S.; White, J.D.; Wright, H.; Clardy, J. Structures of Stemodin and Stemodinone. J. Am. Chem. Soc. 1973, 95, 2705-2706. [CrossRef]

4. Manchand, P.S.; Blount, J.F. X-ray Structure and Absolute Stereochemistry of Stemarin, a Diterpene with a New Skeleton. J. Chem. Soc. Chem. Commun. 1975, 21, 894-895. [CrossRef]

5. Hufford, C.D.; Guerrero, R.O.; Doorembos, N.J. Two new diterpenes from Stemodia maritima L. J. Pharm. Sci. 1976, 65, 778-780. [CrossRef] [PubMed]

6. Sir, J.L.; Barton, D.H.R. The Terpenes, Vol. III, Simonsen; Cambridge University Press: Cambridge, UK, 1961; p. 472.

7. Trost, B.M.; Nishimura, Y.; Yamamoto, K.; McElvain, S.S. A Total Synthesis of Aphidicolin. J. Am. Chem. Soc. 1979, 101, 1328-1330. [CrossRef]

8. McMurry, J.E.; Andrus, A.; Ksander, G.M.; Musser, J.H.; Johnson, M.A. Stereospecific Total Synthesis of Aphidicolin. J. Am. Chem. Soc. 1979, 101, 1330-1332. [CrossRef]

9. Rizzo, C.J.; Smith, A.B., III. A New End Game for Aphidicolin. Tetrahedron Lett. 1988, 29, $2793-2796$. [CrossRef]

10. Rizzo, C.J.; Smith, A.B., III. Aphidicolin synthetic studies: A stereocontrolled end game. J. Chem. Soc. Perkin Trans. 1 1991, 5, 969-979. [CrossRef]

11. Corey, E.J.; Tius, M.A.; Das, J. Total Synthesis of ( \pm )-Aphidicolin. J. Am. Chem. Soc. 1980, 102, $1742-1244$. [CrossRef]

12. Van Tamelen, E.E.; Zawacky, S.R.; Russell, R.K.; Carlson, J.G. Biogenetic-Type Total Synthesis of ( \pm )-Aphidicolin. J. Am. Chem. Soc. 1983, 105, 142-143. [CrossRef]

13. Marini Bettolo, R.; Tagliatesta, P.; Lupi, A.; Bravetti, D. A Total Synthesis of Aphidicolin: Stereospecific

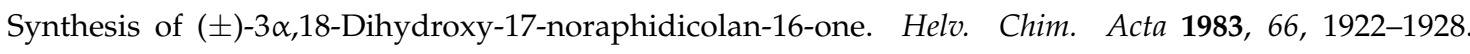
[CrossRef]

14. Lupi, A.; Patamia, M.; Marini Bettolo, R. A Total Synthesis of ( \pm )-Aphidicolin: Regio and Stereoselective Conversion of 3 $\alpha$,18-Di-O-benzyl-17-nor-14-aphidicolen-16-one into ( \pm )-Aphidicolin. Helv. Chim. Acta 1988, 71, 872-875. [CrossRef]

15. Toyota, M.; Nishikawa, Y.; Fukumoto, K. An Expeditious and Efficient Formal Synthesis of ( \pm )-Aphidicolin. Tetrahedron Lett. 1994, 35, 6495-6498. [CrossRef]

16. Toyota, M.; Nishikawa, Y.; Seishi, T.; Fukumoto, K. Aphidicolin Synthesis (I)—Formal Synthesis of (+)-Aphidicolin by the Successive Intramolecular Diels-Alder Ractions. Tetrahedron 1994, 50, 10183-10192. [CrossRef]

17. Toyota, M.; Nishikawa, Y.; Seishi, T.; Fukumoto, K. Aphidicolin Synthesis (II)—An Expeditious and Efficient Formal Synthesis of $( \pm)$-Aphidicolin. Tetrahedron 1994, 50, 11153-11166. [CrossRef]

18. Tanaka, T.; Murakami, K.; Okuda, O.; Inoue, T.; Kuroda, T.; Kamei, K.; Murata, T.; Yoshino, H.; Imanishi, T.; Kim, S.-W.; et al. Synthetic Studies on Aphidicolane and Stemodane Diterpenes. IV. A Stereoselective Formal Total Synthesis of $( \pm)$-Aphidicolin. Chem. Pharm. Bull. 1995, 43, 193-197. [CrossRef]

19. Tanaka, T.; Okuda, O.; Murakami, K.; Yoshino, H.; Mikamiyama, H.; Kanda, A.; Kim, S.-W.; Iwata, C.C. Synthetic Studies on Aphidicolane and Stemodane Diterpenes. V. A Facile Formal Total Synthesis of ( \pm )-Aphidicolin via a Lewis Acid-Mediated Stereoselective Spiroannelation. Chem. Pharm. Bull. 1995, 43, 1407-1411. [CrossRef] 
20. Holton, R.A.; Kennedy, R.M.; Kim, H.B.; Krafft, M.E. Enantioselective Total Synthesis of Aphidicolin. J. Am. Chem. Soc. 1987, 109, 1597-1600. [CrossRef]

21. Tanis, S.P.; Chuang, Y.-H.; Head, D.B. Furans in Synthesis. Formal Total Syntheses of $( \pm)$ - and (+)-Aphidicolin. J. Org. Chem. 1988, 53, 4929-4938. [CrossRef]

22. Toyota, M.; Nishikawa, Y.; Fukumoto, K. Enantioselective total synthetic route to (+)-aphidicolin. Tetrahedron Lett. 1995, 36, 5379-5382. [CrossRef]

23. Corey, E.J.; Tius, M.A.; Das, J. Total Synthesis of ( \pm )-Stemodin and ( \pm )-Stemodinone. J. Am. Chem. Soc. 1980, 102, 7612-7613. [CrossRef]

24. Atwal, K.S.; Marini Bettolo, R.; Sanchez, I.H.; Tsai, T.Y.R.; Wiesner, K. On the construction of the C/D ring systems of chasmanine and napelline by diene addition. Can. J. Chem. 1978, 56, 1102-1113. [CrossRef]

25. Tsai, T.Y.R.; Nambiar, K.P.; Krikorian, D.; Botta, M.; Marini Bettolo, R.; Wiesner, K. A new synthesis of chasmanine and 13-desoxydelphonine: A preferred route to the aromatic intermediate. Can. J. Chem. 1979, 57, 2124-2134. [CrossRef]

26. Sethi, S.P.; Atwal, K.S.; Marini Bettolo, R.; Tsai, T.Y.R.; Wiesner, K. A stereospecific synthesis of napelline. Can. J. Chem. 1980, 58, 1889-1891. [CrossRef]

27. Wiesner, K.; Tsai, T.Y.R.; Huber, K.; Bolton, S.E.; Vlahov, R. Total synthesis of talatisamine, a delphinine type alkaloid. J. Am. Chem. Soc. 1974, 96, 4990-4992. [CrossRef]

28. Tsai, T.Y.R.; Tsai, C.S.J.; Sy, W.W.; Shanbag, M.N.; Liu, W.C.; Lee, S.F.; Wiesner, K. A Stereospecific Total Synthesis of Chasmanine. Heterocycles 1977, 7, 217-226.

29. Wiesner, K. Centenary lecture. Systematic Development of Strategy in the Synthesis of Polycyclic Polysubstituted Natural Products: The Aconite Alkaloids. Chem. Soc. Rev. 1977, 6, 413-430. [CrossRef]

30. Wiesner, K. Total Synthesis of Delphinine-Type Alkaloids by Simple, Fourth Generation Methods. Pure Appl. Chem. 1979, 51, 689-703. [CrossRef]

31. Walborsky, H.M.; Baum, M.E.; Youssef, A.A. Acetolysis of Bicyclo[2.2.2]octyl-2 p-Bromobenzenesulfonate and the Absolute Configurations of Bicyclo[2.2.2]octanol-2 and cis- and trans-Bicyclo[3.2.1]octanol-2. J. Am. Chem. Soc. 1961, 83, 988-993. [CrossRef]

32. Goering, H.L.; Sloan, M.F. Ionic Reactions in Bicyclic Systems. II. Carbonium Ion Reactions in Bicyclo[2.2.2]octane and Bicyclo[3.2.1]octane Derivatives. J. Am. Chem. Soc. 1961, 83, 1397-1401. [CrossRef]

33. Goering, H.L.; Sloan, M.F. Ionic Reactions in Bicyclic Systems. III. Solvolysis of Bicycloöctanyl and Bicycloöctenyl p-Toluenesulfonates. J. Am. Chem. Soc. 1961, 83, 1992-1999. [CrossRef]

34. Kraus, H.L.; Chassin, C.; Chassin, R.; Schmutte, P. Bicyclische Verbindungen, XVIII Solvolytische und reduktive Umlagerung von Bicyclo[2.2.2]octyltosylaten. Liebigs Ann. Chem. 1970, 738, 97-112. [CrossRef]

35. Bell, R.A.; Ireland, R.E. The construction of the C/D ring system present in the diterpenoid alkaloids atisine and garryfoline. Tetrahedron Lett. 1963, 4, 269-273. [CrossRef]

36. De Santis, B.; Iamiceli, A.L.; Marini Bettolo, R.; Migneco, L.M.; Scarpelli, R.; Cerichelli, G.; Fabrizi, G.; Lamba, D. On the Diastereoselectivity of the Aqueous-Acid Catalyzed Intramolecular Aldol Condensation of 3-Oxocyclohexaneacetaldehydes. Helv. Chim. Acta 1998, 81, 2375-2387. [CrossRef]

37. Migneco, L.M.; Leonelli, F.; Marini Bettolo, R. The intramolecular aldol condensation of 3-oxocyclohexaneacetaldehydes: A useful tool in the synthesis of natural products. Arkivoc 2004, 7, $253-265$.

38. Van Tamelen, E.E.; Carlson, J.G.; Russell, R.K.; Zawacky, S.R. Total Synthesis of ( \pm )-Maritimol. J. Am. Chem. Soc. 1981, 103, 4615-4616. [CrossRef]

39. Hanessian, S. Total Synthesis of Natural Products: The "Chiron" Approach; Baldwin, J.E., Ed.; Pergamon: Oxford, UK, 1983.

40. Wenkert, E.; Sternberg, V.; Beak, P. Podocarpic Acid Derivatives. Synthesis of Nimbiol. J. Am. Chem. Soc. 1961, 83, 2320-2325. [CrossRef]

41. Leonelli, F.; Borocci, S.; Migneco, L.M.; Marini Bettolo, R.; Lamba, D. The Formation of 8-Epipodocarp9(11)en-12-one in the Course of the Preparation of Podocarp-9(11)-en-12-one from O-Methylpodocarpane and Related Studies. Helv. Chim. Acta 2002, 85, 2817-2826. [CrossRef]

42. Guthrie, R.W.; Philipp, A.; Valenta, Z.; Wiesner, K. Synthesis in the diterpene alkaloid series III. A novel synthesis of a keto lactam. A photochemical approach to the C,D-ring system of atisine. Tetrahedron Lett. 1965, 34, 2945-2950. [CrossRef]

43. Wiesner, K. On the stereochemistry of photoaddition between $\alpha, \beta$-unsaturated ketones and olefins. Tetrahedron 1975, 31, 1655-1658. [CrossRef] 
44. Marini Bettolo, G.; Sahoo, S.P.; Poulton, G.A.; Tsai, T.Y.R.; Wiesner, K. On the stereochemistry of photoaddition between $\alpha, \beta$-unsaturated ketones and olefins-II. Tetrahedron 1980, 36, 719-721. [CrossRef]

45. Blount, J.F.; Gray, G.D.; Atwal, K.S.; Tsai, T.Y.R.; Wiesner, K. On the stereochemistry of photoaddition between $\alpha, \beta$-unsaturated ketones and olefins. III. Tetrahedron Lett. 1980, 21, 4413-4416. [CrossRef]

46. Valenta, K.; Grein, F. Excited states of acrolein: Ab initio model studies on $\alpha, \beta$-unsaturated carbonyl compounds. Can. J. Chem. 1982, 60, 601-606. [CrossRef]

47. Bravetti, D.; Marini Bettolo, R.; Lupi, A. On the Construction of the C/D-Ring Systems of Aphidicolin and Stemodin. A regio and Stereospecific Synthesis of 17-Noraphidicolan-16-one and 17-Norstemodan-16-one. Helv. Chim. Acta 1982, 65, 371-376. [CrossRef]

48. Marini Bettolo, R.; Tagliatesta, P.; Lupi, A.; Bravetti, D. A Stereoselective Total Synthesis of ( \pm )-Maritimol, $( \pm)$-2-Deoxystemodinone, ( \pm -Stemodinone and ( \pm )-Stemodin. Helv. Chim. Acta 1983, 66, 760-770. [CrossRef]

49. Kelly, R.B.; Harley, M.L.; Alward, S.J. A total synthesis of ( \pm )-stemarin, a diterpenoid with a unique bicyclic C/D ring System. Can. J. Chem. 1980, 58, 755-756. [CrossRef]

50. Kelly, R.B.; Harley, M.L.; Alward, S.J.; Rej, R.N.; Gowda, G.; Mukhopadhyay, A.; Manchand, P.S. Total synthesis of the stemodane-type diterpenoids, $( \pm)$-2-desoxystemodinone, (+)-2-desoxystemodinone, and $( \pm)$-stemodinol. Can. J. Chem. 1983, 61, 269-275. [CrossRef]

51. Kelly, R.B.; Lal, S.; Gowda, G.; Rej, R.N. A synthesis of (+)-aphidicol-15-ene. Can. J. Chem. 1984, 62, $1930-1932$. [CrossRef]

52. Chamy, M.C.; Piovano, M.; Garbarino, J.A.; Gambaro, V. Stemodane diterpenoids from Stemodia Chilensis. Phytochemistry 1991, 30, 1719-1721. [CrossRef]

53. Leonelli, F.; Mostarda, A.; de Angelis, L.; Lamba, D.; Demitri, N.; la Bella, A.; Ceccacci, F.; Migneco, L.M.; Marini Bettolo, R. Proof of the Structure of the Stemodia chilensis Tetracyclic Diterpenoid (+)-19-Acetoxystemodan-12-ol by Synthesis from (+)-Podocarpic Acid: X-ray Structure Determination of a Key Intermediate. J. Nat. Prod. 2016, 79, 1155-1159. [CrossRef] [PubMed]

54. Berettoni, M.; Marini Bettolo, R.; Montanari, V.; Prencipe, T.; Romeo, S. Studies for a Diastereoselective Synthesis of the Tetracyclic Diol Stemarin: A Model Study for a New Preparation of the Key Intermediate and the Synthesis of (+)-18-Deoxystemarin. Helv. Chim. Acta 1991, 74, 1671-1678. [CrossRef]

55. Marini Bettolo, R.; Migneco, L.M.; Moretti, P.; Scarpelli, R. Improved Conversion of 6-endo-Tosyloxybicyclo [2.2.2] octan-2-ones into 6-exo-Acetoxy and 6-exo-Benzoyloxy-bicyclo[2.2.2]octan-2-ones. J. Prakt. Chem. 1999, 341, 687-690. [CrossRef]

56. Steiweiswer, A., Jr.; Walsh, T.D.; Wolfe, J.R., Jr. Stereochemistry of Acetolysis of Alkyl Sulfonates. J. Am. Chem. Soc. 1965, 87, 3682-3685.

57. Oikawa, H.; Ohashi, S.; König, W.A.; Kenmoku, H.; Sassa, T. Diversity of diterpene hydrocarbons in fungus Phoma betae. Tetrahedron Lett. 2001, 42, 2329-2332. [CrossRef]

58. Neverov, A.A.; McDonald, T.; Gibson, G.; Brown, R.S. Catalysis of transesterification reactions by lanthanides-Unprecedented acceleration of methanolysis of aryl and alkyl esters promoted by $\mathrm{La}(\mathrm{OTf})_{3}$ at neutral pH and ambient temperatures. Can. J. Chem. 2001, 79, 1704-1710.

59. Di Stefano, S.; Leonelli, F.; Garofalo, B.; Mandolini, L.; Marini Bettolo, R.; Migneco, L.M. Elusive 6-exo-Hydroxybicyclo[2.2.2] octan-2-ones from the Corresponding Acetates by Methanolysis in the Presence of $\mathrm{CH}_{3} \mathrm{ONa} / \mathrm{La}(\mathrm{OTf})_{3}$. Org. Lett. 2002, 4, 2783-2785. [CrossRef] [PubMed]

60. Leonelli, F.; Caschera, B.; Silvestri, L.; Prastaro, A.; Corso, G.; Ceccacci, F.; la Bella, A.; Migneco, L.M.; Marini Bettolo, R. Synthesis of (+)-13-Stemarene and (+)-18-Deoxystemarin: Expeditious Preparation of the Key 6-exo-Hydroxybicyclo[2.2.2]octan-2-one Ethylene Dithioacetal. Helv. Chim. Acta 2008, 91, 598-607. [CrossRef]

61. Srikrishna, A.; Satyanarayana, G.; Ravi Kumar, P. Enantiospecific synthesis of tricyclo[5.2.1.0 $\left.0^{4,8}\right]$ decanes via acid catalysed rearrangement of isotwistanes. Tetrahedron Lett. 2005, 47, 363-366. [CrossRef]

62. Leonelli, F.; Latini, V.; Trombetta, A.; Bartoli, G.; Ceccacci, F.; la Bella, A.; Migneco, L.M.; Marini Bettolo, R. Diastereoselective Total Synthesis of (+)-13-Stemarene by Fourth Generation Methods: A Formal Total Synthesis of (+)-18-Deoxystemarin. J. Org. Chem. 2011, 76, 6871-6876. [CrossRef] [PubMed]

63. Kodama, O.; Li, W.X.; Tamogami, S.; Akatsuka, T. Oryzalexin S a novel stemarane-type diterpene rice phytoalexin. Biosci. Biotechnol. Biochem. 1992, 56, 1002-1003. [CrossRef] [PubMed] 
64. Tamogami, S.; Mitani, M.; Kodama, O.; Akatsuka, T. Oryzalexin structure: A new stemarane-type diterpene rice phytoalexin and its biogenesis. Tetrahedron 1993, 49, 2025-2032. [CrossRef]

65. Kodama, O.; Suzuki, T.; Miyakawa, J.; Akatsuka, T. Ultraviolet-induced accumulation of phytoalexins in rice leaves. Agric. Biol. Chem. 1988, 52, 2469-2473.

66. Chamy, M.C.; Piovano, M.; Garbarino, J.A.; Miranda, C.; Gambaro, V. Diterpenes from Calceolaria lepida. Phytochemistry 1990, 29, 2943-2946. [CrossRef]

67. Garbarino, J.A.; Molinari, A. Diterpenes from Calceolaria latifolia. Phytochemistry 1990, 29, 3037-3039. [CrossRef]

68. Chamy, M.C.; Piovano, M.; Garbarino, J.A.; Gambaro, V. Diterpenes from Calceolaria polifolia. Phytochemistry 1991, 30, 3365-3368. [CrossRef]

69. Leonelli, F.; Blesi, F.; Dirito, P.; Trombetta, A.; Ceccacci, F.; la Bella, A.; Sferrazza, A.; Lamba, D.; Migneco, L.M.; Marini Bettolo, R. Regio- and Diastereoselective Synthesis and X-ray Structure Determination of (+)-2-Deoxyoryzalexin S from (+)-Podocarpic Acid. Structural Non-identity with Its Nominal Natural Isolated Enantiomer. J. Nat. Prod. 2012, 75, 1944-1950. [CrossRef] [PubMed]

70. Cambie, R.C.; Rutledge, P.S.; Woodgate, P.D. Transformations of podocarpic acid. Aust. J. Chem. 1993, 46, 1447-1471. [CrossRef]

(C) 2016 by the authors; licensee MDPI, Basel, Switzerland. This article is an open access article distributed under the terms and conditions of the Creative Commons Attribution (CC-BY) license (http://creativecommons.org/licenses/by/4.0/). 